\title{
Inter-individual differences in serotonin and glutamate co- transmission reflect differentiation in context-induced conditioned 50-kHz USVs response after morphine withdrawal
}

\author{
Adam Hamed ${ }^{1} \cdot$ Miron Bartosz Kursa ${ }^{2}$
}

Received: 25 October 2017 / Accepted: 9 May 2018 / Published online: 17 May 2018

(c) The Author(s) 2018

\begin{abstract}
A growing body of research provides compelling evidence that in rats $50-\mathrm{kHz}$ USVs are a form of expression of positive emotions. Context-induced $50-\mathrm{kHz}$ USVs emission is variable among rats, indicating individual differences in contextual response bound up with pharmacological reward. The aims of this study were to: extract the most important neurotransmitters related to context-induced conditioned 50-kHz USVs response; find biological basis of existing inter-individual differences in context-induced conditioned 50-kHz USV s response; create a model of all-to-all neurotransmitters correlations. The data collected here confirms that re-exposure to the context of morphine administration after the withdrawal period increases the level of 50-kHz USVs and this contextual response is associated with elevated serotonin concentrations in amygdala, hippocampus and mPFC and with increased Glu/Gln ratio in nucleus accumbens. The concentration of serotonin increases simultaneously in amygdala, nucleus accumbens and hippocampus. Moreover, 5-HT concentration in amygdala is bound up with glutamate level in this structure as well as in hippocampus. Furthermore, Glu/Gln ratio in nucleus accumbens has strong associations with Glu/Gln ratio simultaneously in VTA, amygdala, striatum and hippocampus. All-to-all-analysis indicate that concentration of glutamate in hippocampus is proportional to glutamate in VTA and GABA concentration in the hippocampus. We have also demonstrated that Glu/GABA ratio in VTA and amygdala was elevated after post withdrawal re-exposure to the pharmacological reward paired context. Presented analysis indicates a strong correlation between serotonergic and glutamatergic systems in context-induced conditioned response. The strength of this co-transmission correlates with the number of 50-kHz USVs emitted in response to morphine-paired context.
\end{abstract}

Keywords Amygdala $\cdot$ Morphine $\cdot$ Reward $\cdot$ Context conditioning $\cdot$ USVs $\cdot$ Ultrasonic vocalization · Incubation of craving · Neurochemistry $\cdot$ Machine learning $\cdot$ Serotonin $\cdot$ Glutamate $\cdot$ GABA $\cdot$ Nucleus accumbens $\cdot 5$-HT $\cdot$ Co-transmission $\cdot$ Interindividual differences; $\cdot$ Context-induced $\cdot$ Glu/Gln ratio

\section{Introduction}

A modern behavioral tool that most effectively determines the emotional states of rats is the registration and analysis of ultrasonic vocalizations (USVs). It allows both identifying

Adam Hamed

a.hamed@nencki.gov.pl

1 Laboratory of Spatial Memory, Department of Cellular and Molecular Biology, Nencki Institute of Experimental Biology, Polish Academy of Sciences, 3 Pasteur Street, 02-093 Warsaw, Poland

2 Interdisciplinary Centre for Mathematical and Computational Modelling, University of Warsaw, Pawinskiego 5A, 02-106 Warsaw, Poland individual differences in processing information about the reward as well as reflecting, to a large extent, the level of individual motivation. It is well established that rats emit two district ultrasonic vocalizations patterns (USVs) related to separate emotional tinge: long $22-\mathrm{kHz}$ alarm calls when processing negative emotions and 50-kHz when processing positive emotions (Panksepp and Burgdorf 2003; Brudzynski 2013a, b; Burgdorf et al. 2017). Representations of these sounds are also present in rats' social interactions (Knutson et al. 1998; Brudzynski and Pniak 2002; Hamed et al. 2009, 2015). The mesolimbic reward system is highly involved in the production of $50-\mathrm{kHz}$ ultrasonic vocalizations (USVs) in rats (Knutson et al. 1999; Burgdorf et al. 2001, 2007). Large number of studies indicate that the most potent pharmacological agent that induces $50-\mathrm{kHz}$ USVs 
in rats is amphetamine (Burgdorf et al. 2001; Thompson et al. 2006; Wang et al. 2008; Ahrens et al. 2009; Wright et al. 2010; Brudzynski et al. 2011; Simola et al. 2012; Taracha et al. 2012). In a recent study we conducted nonparametric analysis of neurochemical effects showing that re-exposure to amphetamine induces neurochemical changes in several brain areas (Hamed et al. 2016). We demonstrated that increased concentration of noradrenaline in the nucleus accumbens strongly correlated with the number of $50-\mathrm{kHz}$ USVs (Hamed et al. 2016). Another set of pharmacological experiments demonstrated that noradrenaline related mechanisms are highly involved in 50-kHz USVs emission (Wright et al. 2012a). Previous studies have established that intracerebral injection of glutamate may induce $50-\mathrm{kHz}$ USVs, suggesting that glutamatergic system is also involved in production of these sounds (Fu and Brudzynski 1994; Wintink and Brudzynski 2001). Additionally, administration of the amphetamine with MK-801 (NMDA antagonist) suppressed emission of the $50-\mathrm{kHz}$ USV s compared to amphetamine treated animals, suggesting that glutamatergic system may be highly engaged in 50-kHz USV s emission (Costa et al. 2015). Co-administration of those two substances suppressed likewise context-induced conditioned 50-kHz USVs when animals were re-exposed to the drug-paired chamber (Costa et al. 2015). Moreover, there are evidence showing that antagonism of 5-HT $2 \mathrm{C}$ or the $\kappa$-opioid receptors increases emission of 50-kHz USVs (Wöhr et al. 2015; Hamed et al. 2015). Furthermore, agonist of 5-HT2C receptor suppressed amphetamine induced sounds in this frequency band (Wöhr et al. 2015).

A growing body of research provides compelling evidence that $50-\mathrm{kHz}$ USVs (Fig. 1) are a form of expression of positive emotions. However, pharmacological studies indicate that processing of positive emotions is not always accompanied by the $50-\mathrm{kHz}$ USVs in rats. In case of morphine treatment, higher doses of this addictive drug $(10 \mathrm{mg} /$ $\mathrm{kg}$ ) decreased the sounds triggered by social interaction (Hamed et al. 2015). It has been also demonstrated that MDMA, which induces huge arousal (excitation) in humans, did not evoke an increase in total number of $50-\mathrm{kHz}$ USVs (Sadananda et al. 2012; Simola et al. 2012).

In the canonical conviction, dopaminergic reward system, originating from ventral tegmental area (VTA) is crucial for reward processing (Schultz et al. 1997; Dayan and Balleine 2002; Cohen et al. 2012; Lammel et al. 2012). The latest reports have shown that another structure-dorsal raphe might be equally treated as a key structure in reward processing and reward expectation (Luo et al. 2015, 2016; Li et al. 2016; Matthews et al. 2016; Qi et al. 2014). In mice with dopamine deficiency SSRIs (selective serotonin reuptake inhibitors) have produced robust conditioned place preference. This indicates that serotonin or serotonin-related mechanisms may mediate reward in the absence of dopamine (Hnasko et al. 2007).

It is well known that addictive drugs like morphine affect numerous neurochemical pathways, including those related to the reward system (Koob 1992). Morphine as MOR ( $\mu$-opioid) agonist has been shown to increase dopamine transmission via mechanisms of decreasing the release of GABA onto dopamine neurons in the VTA (Johnson and North 1992).

Acute administration of high doses of morphine (over $1.0 \mathrm{mg} / \mathrm{kg}$ ) inhibited or did not evoke 50-kHz USVs (Nagai et al. 2004; Wright et al. 2012b; Simola et al. 2012; Hamed et al. 2012). Our previous studies showed that when morphine was administered for 14 days (once a day), an increase in the number of USVs episodes, recorded after drug injection, was observed on the 14th day as compared to the 1st

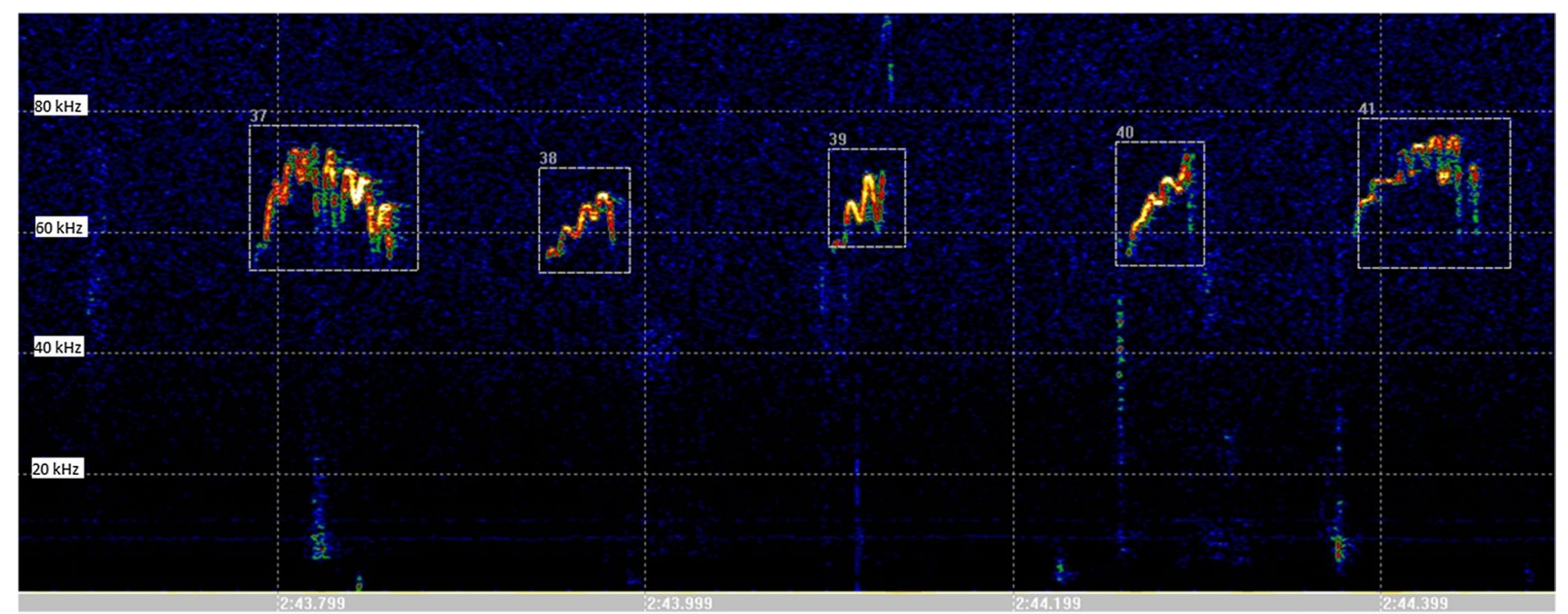

Fig. 1 An example of 50-kHz ultrasonic vocalization episodes 
and the 7th day (Hamed et al. 2012). Additionally, we have demonstrated that morphine-treated rats emitted much more ultrasonic vocalization in $50-\mathrm{kHz}$ band in response to the context of morphine administration after withdrawal period compared to the same measurement before withdrawal period (Hamed et al. 2012). The neurochemical cause of this behavioral phenomenon still remains unknown. Moreover, several studies have shown that $50-\mathrm{kHz}$ USVs are emitted during anticipation of the natural, pharmacological reward or even rewarding electrical brain stimulation (Burgdorf et al. 2000; Knutson et al. 1999; Opiol et al. 2015; Buck et al. 2014; Hamed et al. 2012). Simultaneously, existence of individual differences in the emission of $50-\mathrm{kHz}$ USVs between rats further complicates the interpretation of behavioral data. Nevertheless, the fact that there are individual differences in the emission of the $50-\mathrm{kHz}$ USV allows us to explore neurochemical differences in structures related to reward processing, enabling us to explore biological basis of that phenomenon.

Taking into account that morphine pre-treated rats emitted much more context-induced $50-\mathrm{kHz}$ USV s on the challenge day (after 14 day withdrawal period) and the aforementioned literature facts about pharmacological modifications of $50-\mathrm{kHz}$ USVs we conducted non-parametric analysis between concentrations of neurochemical compounds in several brain structures (see "Materials and methods") with the level of context-induced conditioned 50-kHz USVs. We hypothesized that the $50-\mathrm{kHz}$ USVs emission could have separate neurochemical background in different behavioral paradigms as well as some common neurochemical mechanisms reflected in examined neurotransmitters correlations.

The aims of this study were to: (1) extract the most important neurotransmitters that are bound up with context-induced conditioned 50-kHz USVs related with pharmacological reward; (2) find biological basis of occurring inter-individual differences in context-induced conditioned 50-kHz USVs response; (3) create a model of all-to-all neurotransmitters correlations.

\section{Materials and methods}

\section{Animals}

Adult male Sprague-Dawley rats $(n=38 ; 180 \pm 20 \mathrm{~g})$ were used in the experiment. The animals were purchased from a licensed breeder (the Polish Academy of Science Medical Research Center, Warsaw, Poland). The animals were housed in standard laboratory conditions under $12 \mathrm{~h}: 12 \mathrm{~h}$ light:dark cycles (lights on at 7 a.m.) at a constant temperature $\left(21 \pm 2{ }^{\circ} \mathrm{C}\right)$ and $70 \%$ humidity. The rats had free access to food and water. The experiments were performed in accordance with the European Communities Council Directive of
24 November 1986 (86/609 EEC). The Local Committee for Animal Care and Use of Warsaw Medical University approved all experimental procedures using animal subjects.

\section{Experimental procedure}

Groups of five animals were housed in acrylic cages (cage size: $54 \mathrm{~cm} \times 34 \mathrm{~cm} \times 21 \mathrm{~cm}$ ) for 2 weeks. Morphine in dose $10.0 \mathrm{mg} / \mathrm{kg}$ (s.c.) was administered repeatedly to the experimental groups. Morphine and saline were administered in testing cages in a group of four animals for each cage. The testing room was significantly different than home cage room, both in the lighting conditions and in the arrangement of spatial cues that were constant throughout the whole experiment. The testing room was situated in a remote part of the laboratory. In Morph-D14 group, 13 injections were administered once a day. In the Morph-D28 group morphine was administered once a day for 14 days $(10 \mathrm{mg} / \mathrm{kg} \mathrm{s.c})$. Saline solution was administered repeatedly $(1.0 \mathrm{ml} / \mathrm{kg})$ to control groups (Saline-D14 and) in the same manner as morphine in morphine treated rats. All animals were kept for $30 \mathrm{~min}$ in the testing box after each saline or morphine injection.

On day 14, Morph-D14 group and control Saline-D14 group were exposed to the context of drug administration, and the ultrasonic vocalizations were recorded for $20 \mathrm{~min}$. Immediately after $20 \mathrm{~min}$ of USVs recording session rats from Morph-D14 and Saline-D14 groups were decapitated. On day 14, 30 min after last injection Morph-D28 and Saline-D28 group were left undisturbed (in their home cages), whilst they were subjected to 2-week withdrawal period. On day 28, the rats were re-exposed to the context of morphine/saline administration and ultrasonic vocalization was recorded for $20 \mathrm{~min}$. Immediately after $20 \mathrm{~min}$ of USVs recording session rats from Morph-D28 and Saline-D28 groups were decapitated (Fig. 2). The USVs were recorded in a dark room with a dim red light [ $30 \mathrm{~W}$ bulb $1.5 \mathrm{~m}$ above the acrylic cage (size: $54 \mathrm{~cm} \times 34 \mathrm{~cm} \times 21 \mathrm{~cm}$ )]. The USV s response to the context was measured separately for each rat. To avoid the influence of scent marks from other animals on the behavior of subsequently tested rats, cages were cleaned with a $70 \%$ ethanol solution after each recorded session. Brain tissues were frozen in dry ice-cold isopentane, and stored at $-70{ }^{\circ} \mathrm{C}$ for neurochemical analysis.

\section{Drugs}

Morphine hydrochloride (Polfa, Poland) was dissolved in $0.9 \%$ isotonic saline. Morphine was administered in dose of $10.0 \mathrm{mg} / \mathrm{kg}$ (1.0 ml $/ \mathrm{kg}$; s.c.). Saline was used as a control vehicle $(1 \mathrm{ml} / \mathrm{kg})$. 


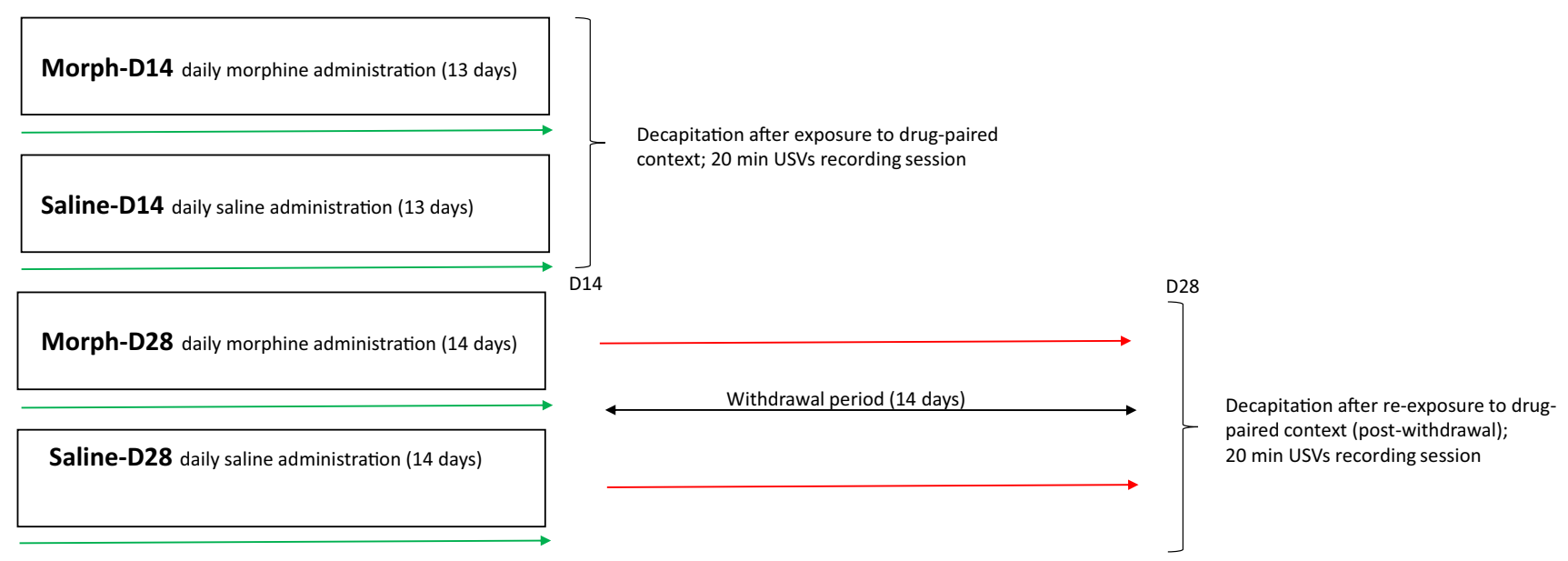

Fig. 2 Diagram of the experiment

\section{Apparatus and USVs recordings}

All subtypes of $50 \mathrm{kHz}$ rat calls were recorded using an UltraSoundGate Condenser Microphone CM16 (Avisoft Bioacoustics, Berlin, Germany) that was positioned 25-30 cm above the floor of the cage. This microphone was sensitive to frequencies of $15-180 \mathrm{kHz}$ with a flat frequency response $( \pm 6 \mathrm{~dB})$ between 25 and $140 \mathrm{kHz}$. It was connected to an amplifier (custom-made) that had the following parameters: a voltage gain of $16 \mathrm{~V} / \mathrm{V}(12 \mathrm{~dB})$, a frequency response of $\pm 0.1 \mathrm{~dB}$, a range of $30 \mathrm{~Hz}$ to $120 \mathrm{kHz}$, and an input impedance of $600 \Omega$. The signal was then transferred through a $120 \mathrm{kHz}$ anti-aliasing filter (custom-made). The filtered sounds were sent to a PCI-703-16A data acquisition board (Eagle Technology, USA). This board was a 14-bit $400-\mathrm{kHz}$ analogue input and analogue output board for PCI-based systems. The recorded data were processed using the RAT-REC PRO 5.0 software (custom-made). The signals were processed through a fast Fourier-transformation (1024, Hamming window) and displayed as color spectrograms. Each signal was manually marked with the section label included in the automated parameter measurement. Various parameters were determined automatically, including the number of USV calls, the total calling time (s), the mean call length $(\mathrm{s})$, the frequency bandwidth $(\mathrm{kHz})$, the number of gaps, the mean gap length (s), and the mean peak frequency $(\mathrm{kHz})$. Only the number of calls is included as a main parameter in the results presented here. Taking into account that dopaminergic system plays role in the processing of both appetitive and aversive states (BrombergMartin et al. 2010; Zweifel et al. 2011; Lammel et al. $2011 \mathrm{a}, \mathrm{b})$, we have analyzed FFT spectrograms in whole recorded frequency spectrum $(10-130 \mathrm{kHz})$ to evaluate occurrence not only " $50-\mathrm{kHz}$ appetitive", but also "22$\mathrm{kHz}$ aversive" calls. Detailed analysis of the FFT spectrograms showed the absence of $22-\mathrm{kHz}$ (alarm calls) in presented model.

\section{HPLC analysis of monoamines}

Frozen brains were cut into slices $\left(-20{ }^{\circ} \mathrm{C}\right)$ in a cryostat. The following structures were dissected: prefrontal cortex (3.7-3.2 $\mathrm{mm}$ anterior to the bregma); nucleus accumbens (NAcc) and caudate putamen $(\mathrm{CPu})(1.70-1.0 \mathrm{~mm}$ anterior to the bregma); hippocampus and amygdala ( -2.80 to $-3.60 \mathrm{~mm}$ posterior to the bregma); and ventral tegmental area $(-5.80$ to $-6.30 \mathrm{~mm}$ posterior to the bregma) based on the rat brain atlas of Paxinos and Watson (1998). Tissue samples were weighed and homogenized for $30 \mathrm{~s}$ in 15 volumes of ice-cold $0.2 \mathrm{M}$ perchloric acid, which contained dihydroxybenzylamine as an internal standard. The homogenates were then centrifuged at $26,900 \mathrm{~g}$ for $8 \mathrm{~min}$ at $4{ }^{\circ} \mathrm{C}$. The supernatants were then filtered through $0.45-\mu \mathrm{m}$ pore filters and stored at $-70{ }^{\circ} \mathrm{C}$ until analyzed for noradrenaline (NA), 3-methoxy-4-hydroxyphenylglycol (MHPG), dopamine (DA), 3,4-dihydroxyphenylacetic acid (DOPAC), homovanillic acid (HVA), 3-methoxytyramine (3-MT), serotonin (5-HT) and 5-hydroxyindoleacetic acid (5-HIAA) using HPLC, as described by Kaneda et al. (1986), with minor modifications (Szyndler et al. 2010). The concentrations of NA, MHPG, DA, DOPAC, 3-MT, HVA, 5-HT and 5-HIAA were calculated as ng/g of brain tissue. Additionally, to approximate their turnover, the following concentration ratios were computed: 3 -MT to DA, DOPAC to DA, HVA to DA, 5-HIAA to 5-HT and MHPG to NA. 


\section{HPLC analysis of amino acids}

The brain levels of the amino acids were determined using HPLC method, coupled to an electrochemical detection, as described previously (Szyndler et al. 2008). Briefly, the compounds were eluted isocratically with the mobile phase delivered at $0.7 \mathrm{ml} / \mathrm{min}$, using a Shimadzu Class LC-10ADvp pump. An electrochemical detector with a flow-through cell (Intro-Antec Leyden) linked to the Shimadzu Class VP Integrator SCL-10 Avp was used. A high-density glass carbonworking electrode (Antec) was used at $+0.85 \mathrm{~V}$. A Rheodyne injection valve with $20-\mu \mathrm{l}$ sample loops was used to manually inject the samples. The preparation of the mobile phase and the derivatizing agents was based on the slightly modified method of Rowley et al. (1995; Szyndler et al. 2008). The concentrations of GABA, alanine, taurine, glutamine and glutamate were calculated in $\mu \mathrm{mol} / \mathrm{g}$ of tissue. Similarly as in case of monoamines, ratios of the glutamate concentration to both glutamine and GABA were also computed and investigated.

\section{Statistics}

All levels of compounds across brain structures and the aforementioned level ratios formed a set of 130 descriptors of the brain state. One should note, however, that the introduction of ratios has created certain artificial correlations, disallowing descriptor independence assumptions.

According to a Shapiro-Wilk test, distributions of most (53\%) of the predictors analyzed in this study are not normally distributed, hence non-parametric statistical approaches were predominantly used.

Relations between numerical variables were assessed using the Spearman correlation, as it is not only robust to non-normality, but can be effectively assessed in terms of significance assuming independence as a null hypothesis, even exactly for small sample sizes.

On the other hand, relations between numerical and binary variables were assessed using the Mann-Whitney-Wilcoxon test.

Still, these tests do not consider possible multivariate associations; to this end, the Boruta machine learning method was employed (Kursa and Rudnicki 2010).

It works by iterative fitting of the Random Forest (Breiman 2001) model to the data, and extracting variables that are significantly more useful for that purpose than shadows, design injected into the dataset. When not specified otherwise, Holm-Bonferroni method was used to correct for multiple comparisons, and the significance level was set at $p=0.05$. All computations were performed using R 3.4.1 ( $\mathrm{R}$ Core Team 2017) with the Boruta 5.2.0 (Kursa and Rudnicki 2010), pspearman 0.3-0 (Savicky 2014) and ranger 0.8.0 packages (Wright and Ziegler 2017).

\section{Results}

\section{The effects of morphine administration and withdrawal period on context-induced conditioned 50-kHz USVs}

The effects of morphine and withdrawal period on contextinduced conditioned 50-kHz USVs count has been analyzed with a series of 6 Mann-Whitney-Wilcoxon tests, and corrected for multiple comparisons. The only non-significant difference between USV counts (number of $50-\mathrm{kHz}$ USVs episodes) in experimental groups was observed between saline and morphine groups on day 14. Between day 14 and day 28 , the USV count has increased both in saline $(p=0.03)$ and morphine $(p=0.002)$ groups, while on day 28 the morphine-treated rats have vocalized more frequently than saline-treated ( $p=0.02)$ (Figs. 3, 4).

\section{The correlations between USV counts and neurotransmitter levels}

Next, the links between USV count and levels or level ratios of the analyzed compounds in across brain structures were assessed. To this end, Spearman correlation test was used, also allowing for extracting the sign of correlation. Additionally, the Boruta machine learning method was used to investigate potential multivariate interactions. Such analysis was performed for all rats, as well as in context of morphineand saline-treated group.

The strongest, significant correlations with USV count were: with 5-HT level in amygdala, hippocampus (for all rats) and medial prefrontal cortex (for morphine group), as well as with 5-HIAA in hippocampus (for all rats). Furthermore, we found USV count to be significantly correlated with the Glu/Gln ratio in nucleus accumbens for morphine group. The raw data behind this interactions are shown on Fig. 4. All these results were also confirmed by the Boruta analysis, along with a number of lesser interaction, collected in Table 1.

\section{The effect of the re-exposure to the morphine-paired context on neurotransmitters levels}

Similar analysis was performed to analyze which compounds can be linked with context-induced conditioned response. This is a classification problem, hence Mann-Whitney-Wilcoxon test was used instead of Spearman correlation. The Boruta method can handle both classification and regression problems, so the auxiliary analysis involving this approach was performed exactly in the same way as in the previous case. Again, contexts of all rats, morphine and saline groups 
Fig. 3 Observed "50-kHz" USV episode counts (number of episodes), for the 14 th (d14) and 28th (d28) day of the experiment, and for saline- and morphine-injected rats. USV count is shown using an inverse hyperbolic sine (IHS) scale.

Bars mark significant differences according to Mann-Whitney-Wilcoxon test

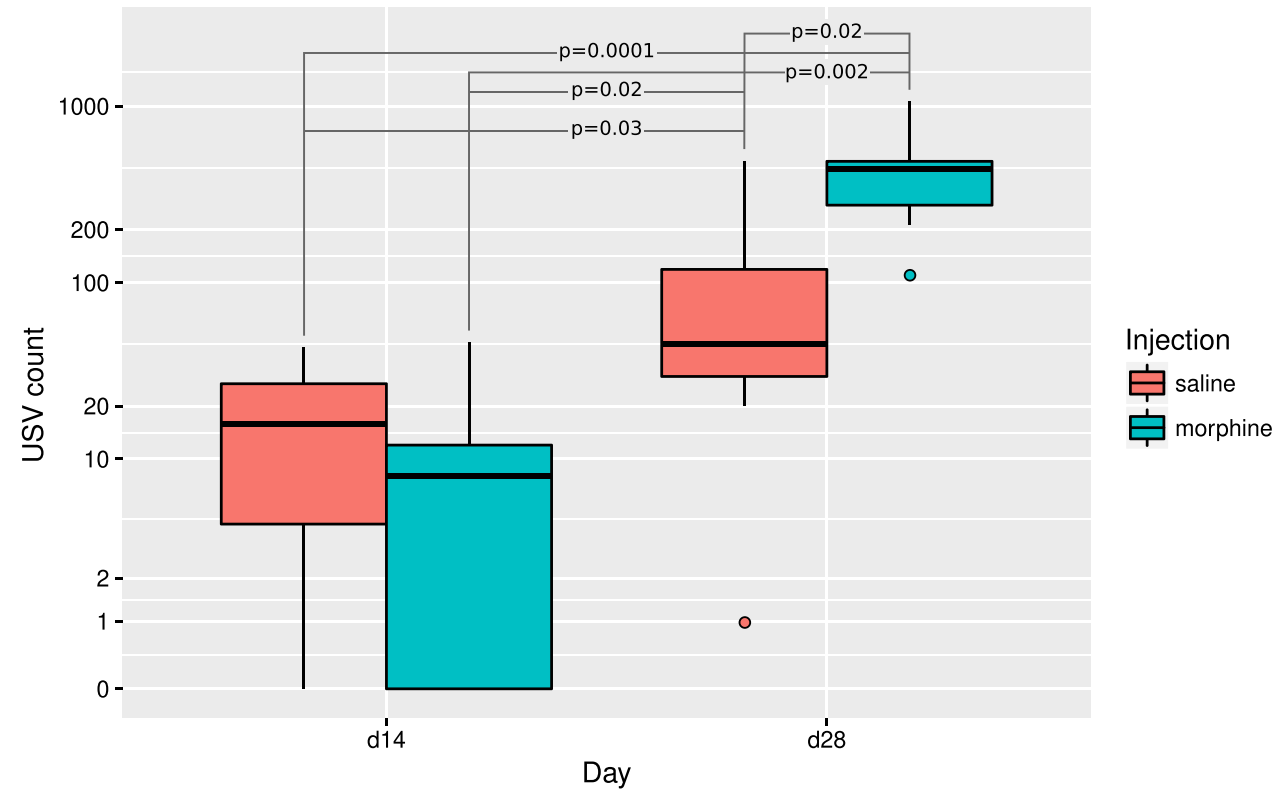

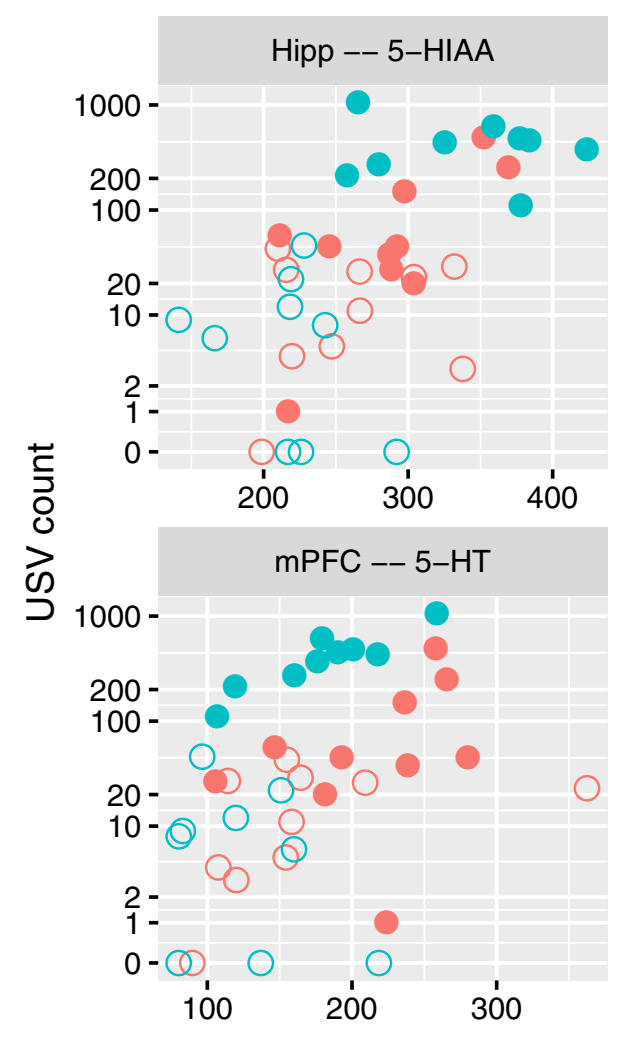
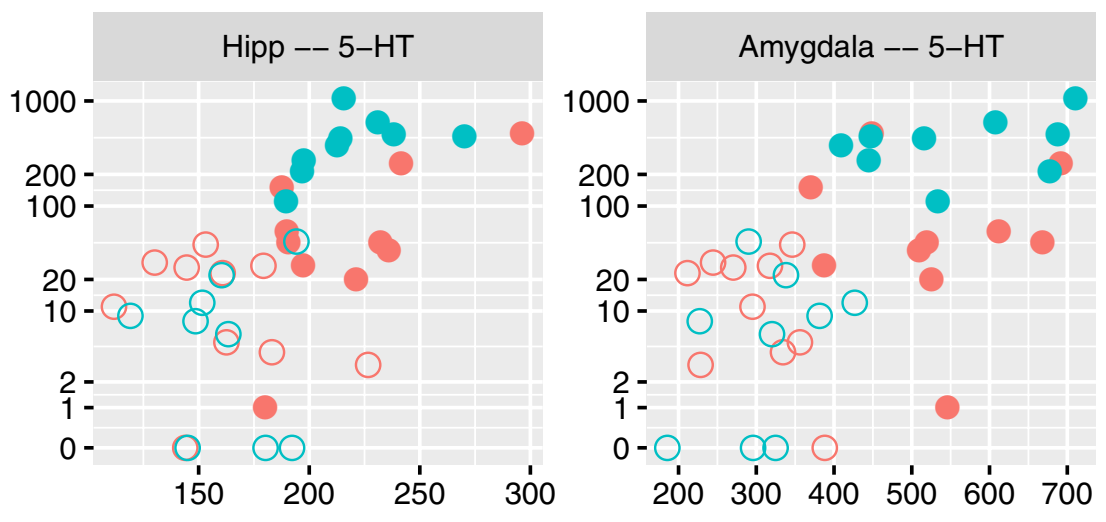

$1_{1.4}^{\prime} \quad 1.5 \quad 1.6 \quad 1.7 \quad 1.8$

Compound level [ng/g tissue]

Day $\bigcirc$ d14 $\bullet$ d28 Injected $\bigcirc$ saline $\bigcirc$ morphine

Fig. 4 Relation between USV count (number of 50-kHz USVs episodes) and levels of compounds or level ratios which were significantly correlated with it, shown as scatterplots. USV count is shown using IHS scale 
Table 1 The selection of brain compounds which level or level ratio is significantly linked with the USV count

\begin{tabular}{|c|c|c|c|}
\hline & Episode count & ...morph group & ...saline group \\
\hline Amygdala - 5-HIAA & $@$ & & \\
\hline Amygdala - 5-HT & $+@$ & $+@$ & \\
\hline Amygdala - Asp & & & $@$ \\
\hline Amygdala - DOPAC/DA & & $@$ & \\
\hline Amygdala - Glu/Gln & $@$ & & \\
\hline Amygdala - Taurine & & & $@$ \\
\hline $\mathrm{Cpu}-5$-HIAA & $@$ & & \\
\hline Hipp - 5-HIAA & $+@$ & $@$ & \\
\hline Hipp - 5-HT & $+@$ & $+@$ & \\
\hline Hipp - DA & $@$ & @ & \\
\hline Hipp - Glu/Gln & $@$ & & \\
\hline $\mathrm{mPFC}-5-\mathrm{HT}$ & $@$ & $+@$ & \\
\hline $\mathrm{mPFC}-\mathrm{Ala}$ & & $@$ & \\
\hline $\mathrm{mPFC}-\mathrm{DOPAC} / \mathrm{DA}$ & & & $@$ \\
\hline Nacc - Glu/Gln & $@$ & $+@$ & \\
\hline VTA - 5-HIAA & & $@$ & \\
\hline $\mathrm{VTA}-5$-HT & & @ & \\
\hline VTA - Ala & & $@$ & \\
\hline
\end{tabular}

“+” denotes positive correlation, “@” association identified with the Boruta method

were investigated separately. Especially, we found positive associations between context conditioning and serotonin levels in amygdala, hippocampus and mPFC, as well as with Glu/Gln ratio in nucleus accumbens, both for all rats and only morphine group. The other interesting effects are: increase of Glu/GABA ratio in VTA and in amygdala for all rats, increased glutamate in amygdala for all rats and only for morphine group, decrease of GABA in VTA and mPFC for all rats and only for morphine group. The said analysis yield numerous significant results, which are summarized in Table 2.

\section{The effects within neurotransmitter levels}

Based on the results highlighted above and theoretical considerations, four substantial descriptors were selected: 5-HT and glutamate levels in amygdala, the ratio of glutamate and glutamine levels in nucleus accumbens, finally the levels of glutamate in hippocampus. For these, sets of other descriptors that significantly correlated with each of them were identified. To this end, Spearman correlation-based methodology identical to previously used for associations with the USV count was applied. All significant correlations with the serotonin level in amygdala are presented in Fig. 5; they include positive correlations with 5-HT levels in other structures (Nacc, Cpu and hippocampus), serotonin metabolite 5-HIAA in amygdala, as well as with the levels of glutamate in both amygdala and hippocampus. On the other hand, negative correlations were observed with the levels of taurine, alanine and GABA in medial prefrontal cortex. Figure 6 contains all the significant correlations with the level of glutamate in amygdala; similarly, it was correlated positively with levels of 5-HT and glutamine, and negatively with levels of alanine and taurine in $\mathrm{mPFC}$. A positive correlation with the level of
Table 2 The selection of brain compounds which level or level ratio is significantly linked with post-withdrawal conditioned response to the context

\begin{tabular}{|c|c|c|c|}
\hline & Day 14 vs. day 28 & ...morph group & .saline group \\
\hline Amygdala - 3-MT & & & \\
\hline Amygdala - 5-HIAA & $+@$ & + & $+@$ \\
\hline Amygdala - 5-HIAA/5-HT & -@ & & \\
\hline Amygdala - 5-HT & $+@$ & +@ & $+@$ \\
\hline Amygdala - Ala & & & $+@$ \\
\hline Amygdala - DA & & & -@ \\
\hline Amygdala - DOPAC/DA & & -@ & $+@$ \\
\hline Amygdala - Glu & $+@$ & $+@$ & @ \\
\hline Amygdala - Glu/GABA & + & & \\
\hline Amygdala - Gly & & & + \\
\hline Amygdala - HVA & & & $-@$ \\
\hline Cpu-5-HIAA & $+@$ & $+@$ & $+@$ \\
\hline $\mathrm{Cpu}-5$-HIAA/5-HT & - & & 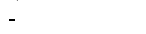 \\
\hline $\mathrm{Cpu}-5$-HT & +@ & & $+@$ \\
\hline Cpu - Taurine & & & - \\
\hline Hipp - 5-HIAA & $+@$ & $+@$ & \\
\hline Hipp - 5-HT & $+@$ & $+@$ & $+@$ \\
\hline Hipp - DOPAC & @ & & \\
\hline Hipp - Glu/Gln & + & & \\
\hline Hipp - Taurine & + & & \\
\hline $\mathrm{mPFC}-3-\mathrm{MT}$ & & & + \\
\hline $\mathrm{mPFC}-3-\mathrm{MT} / \mathrm{DA}$ & & & + \\
\hline $\mathrm{mPFC}-5$-HIAA/5-HT & & & -@ \\
\hline $\mathrm{mPFC}-5$-HT & $+@$ & $+@$ & \\
\hline $\mathrm{mPFC}-\mathrm{Ala}$ & -@ & -@ & \\
\hline $\mathrm{mPFC}-\mathrm{DA}$ & + & & \\
\hline $\mathrm{mPFC}-\mathrm{GABA}$ & -@ & - & \\
\hline $\mathrm{mPFC}-\mathrm{Gln}$ & - & - & \\
\hline $\mathrm{mPFC}$ - Taurine & $-@$ & & $-@$ \\
\hline Nacc - 5-HIAA & & + & \\
\hline $\mathrm{Nacc}-5$-HT & & + & \\
\hline $\mathrm{Nacc}-\mathrm{Ala}$ & - & & \\
\hline Nacc - Gln & - & & \\
\hline $\mathrm{Nacc}-\mathrm{Glu} / \mathrm{Gln}$ & $+@$ & $+@$ & \\
\hline Nacc-Gly & $-@$ & $-@$ & \\
\hline Nacc - HVA & & & $@$ \\
\hline Nacc-MHPG & - & & \\
\hline VTA - 5-HIAA & & + & \\
\hline $\mathrm{VTA}-5$-HT & & $+@$ & \\
\hline VTA - Ala & -@ & -@ & \\
\hline VTA - GABA & & . & \\
\hline VTA - Glu/GABA & $+@$ & & \\
\hline VTA - Glu/Gln & & $+@$ & \\
\hline VTA - HVA & & + & \\
\hline VTA - HVA/DA & & + & \\
\hline
\end{tabular}

"+" denotes positive correlation, "_" negative, while "@” association identified with the Boruta method

taurine in amygdala was also detected. The correlations of Glu/Gln ratio in nucleus accumbens are collected in Fig. 7. This set contains positive correlations with the same ratio in other structures: amygdala, Cpu, hippocampus and VTA, as well as negative with glutamine in $\mathrm{mPFC}$ and $\mathrm{Cpu}$; also a positive correlation with serotonin and 5-HIAA in amygdala was identified. An interesting finding is a correlation between Glu/Gln in Nacc and MHPG/NA ratio in Cpu. Finally, all significant correlations of Glu levels in hippocampus are collected in Fig. 8; they include positive correlations with: MHPG/NA ratio in Cpu; GABA, glutamine, taurine level and Glu/GABA ratio in hippocampus; glutamate level in VTA, serotonin concentration in amygdala.

\section{Intra-neurotransmitter level correlation structure}

Finally, a global, all with all correlation scan was performed. To avoid artificial correlations, the ratios were discarded for 


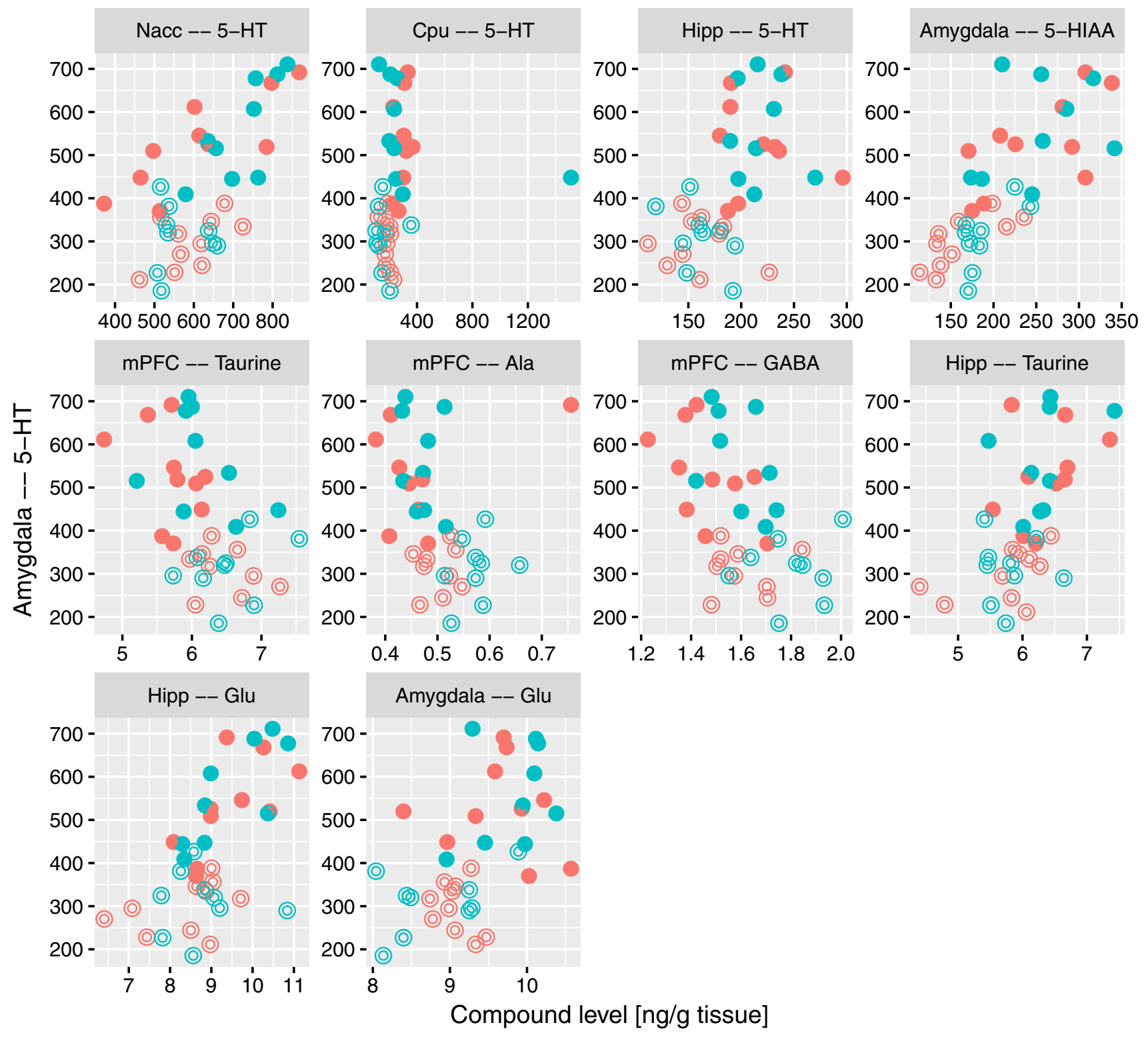

Day $\odot \mathrm{d} 14 \odot \mathrm{d} 28 \quad$ Injected $\bigcirc$ saline $\bigcirc$ morphine

Fig. 5 Relation between the level of 5-HT in amygdala and levels of compounds which were significantly correlated with it, shown as scatterplots

this analysis. It was also performed using Spearman correlation test, although the Benjami Hochberg's multiple comparison correction (FDR) (Benjamini and Hochberg 1995) was used. The results of conducted analysis were compiled into a graph, nodes of which correspond to compound levels across structures, while edges to correlations significant at $p=0.03$ level. The graph was manually laid out to expose relevant coherent structures, and presented in Fig. 9.

\section{Discussion}

The data collected here confirms our previous behavioral results that re-exposure to the context of morphine administration after the withdrawal period (day 28) increases the level of 50-kHz USVs episodes, compared to day 14 (Fig. 3) (Hamed et al. 2012). Context-induced 50-kHz USVs emission is variable among rats, what indicates individual differences in context conditioned response. This kind of gradation allows us to analyze individual differences in brain 


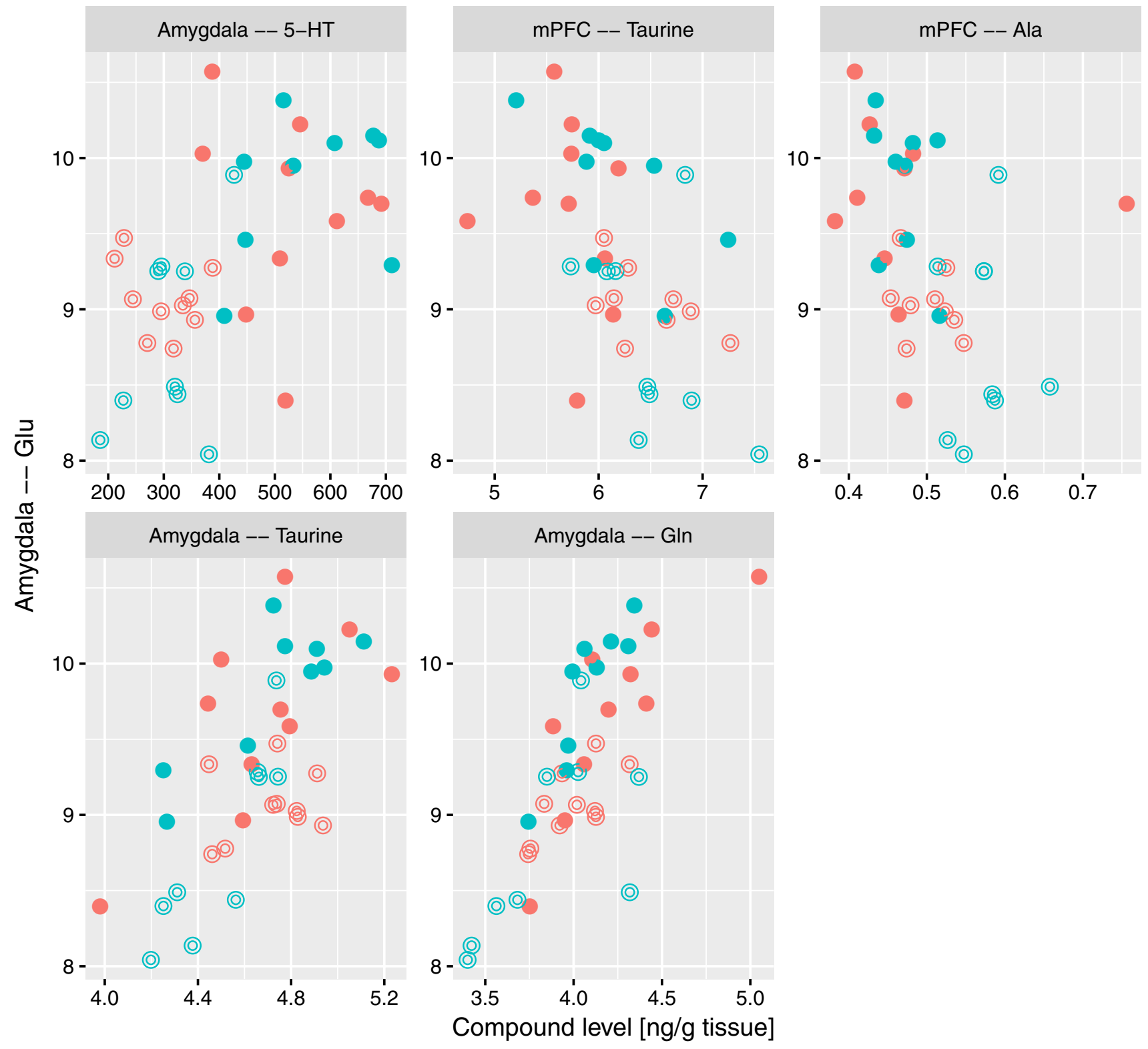

Day $\odot \mathrm{d} 14 \bigcirc \mathrm{d} 28 \quad$ Injected $\bigcirc$ saline $\bigcirc$ morphine

Fig. 6 Relation between the level of glutamate in amygdala and levels of compounds which were significantly correlated with it, shown as scatterplots

neurotransmission and understand the basis of occurring variations in response to the context.

Interestingly, in control saline group an increase of $50-\mathrm{kHz}$ USV s was also observed on day 28 compared to day 14 . One of the reasons might be that both morphine and saline were administered in testing cages in a group of four animals for each cage (see "Materials and methods"). This explanation could suggest that the context conditioned response was enhanced by the natural social contact associated with a different, uncommon environment. Considering rewarding effects of morphine reflected by $50-\mathrm{kHz}$ USVs emission reported in our previous studies (Hamed et al. 2012), we can be sure that emitted sounds reflect contextinduced conditioned response related to morphine rewarding effects. This kind of behavioral $50-\mathrm{kHz}$ USV s response was reported in studies with natural, pharmacological reward or even with rewarding electrical brain stimulation (Knutson et al. 1999; Burgdorf et al. 2000; Opiol et al. 2015; Buck et al. 2014). The level of emitted 50-kHz USVs was over ten times higher in morphine-treated group than in saline group 


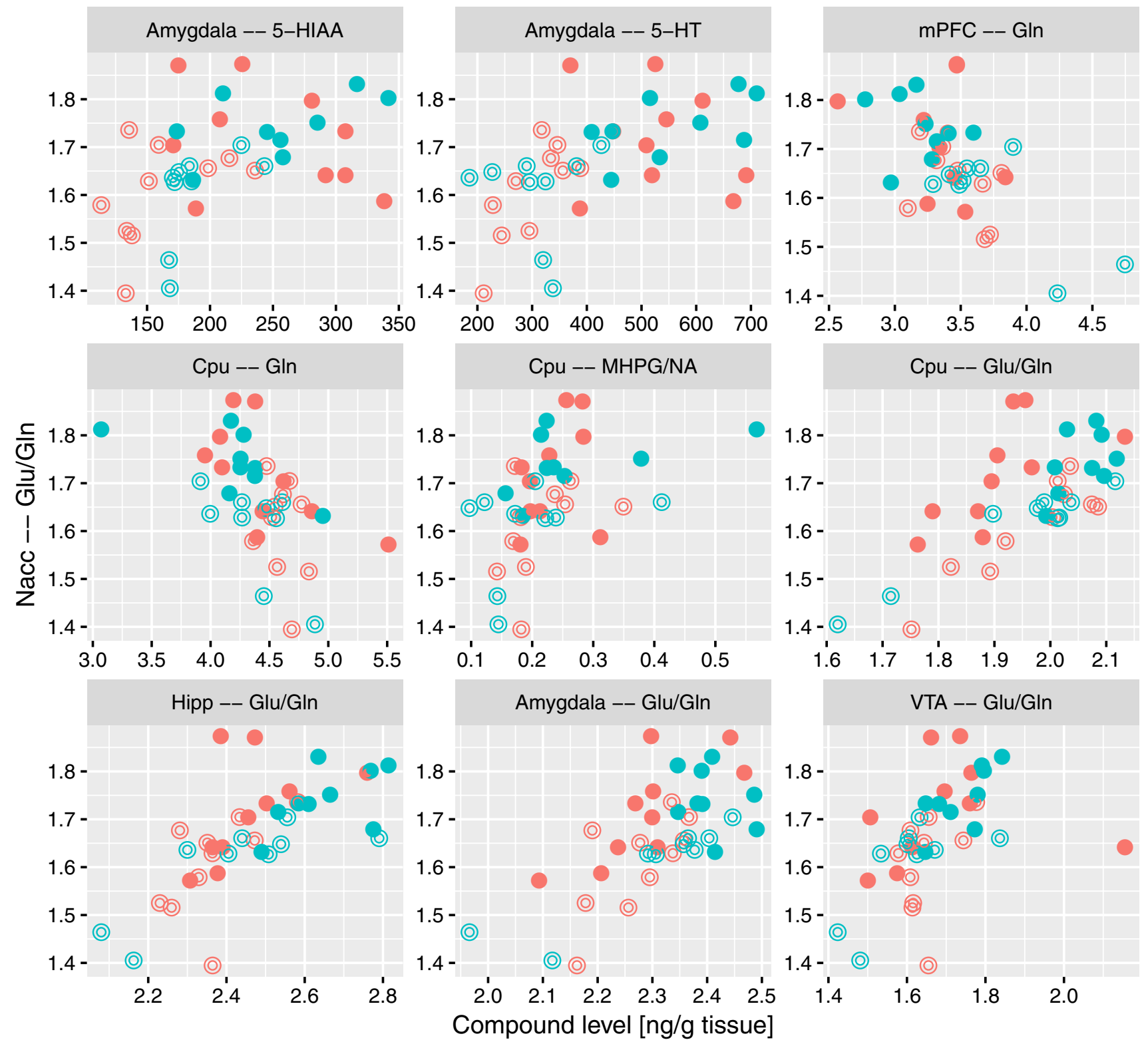

Day $\bigcirc$ d14 $\bullet$ d28 Injected $\bigcirc$ saline $\bigcirc$ morphine

Fig. 7 Relation between the ratio of glutamate to glutamine level in nucleus accumbens and levels of compounds or level ratios which were significantly correlated with it, shown as scatterplots

and only three of saline control animals produced more than hundred USVs episodes (Figs. 3, 4). The starting point of our correlations analysis was the level of context conditioned response reflected by $50-\mathrm{kHz}$ USVs emission. All further consecutive analysis were conducted in the same way in the morphine and saline-treated animals (Figs. 4, 5, 6, 7, 8, 9; Tables 1,2).

Nevertheless, the fact that emission of $50-\mathrm{kHz}$ USVs is a context-induced conditioned response, it is interesting why re-exposure to the drug-paired context did not evoke such sounds on day 14 in the same manner as on day 28 (after 14 day-withdrawal period; Figs. 3, 4). This time-dependent differentiation effect of observed behavior may be explained by the phenomenon defined as "incubation of drug craving". It was demonstrated in humans that craving may be triggered by drug-associated cues and may increase progressively during the early days of withdrawal (Gawin and Kleber 1986; Abrams et al. 1988; Drummond et al. 1990; George et al. 


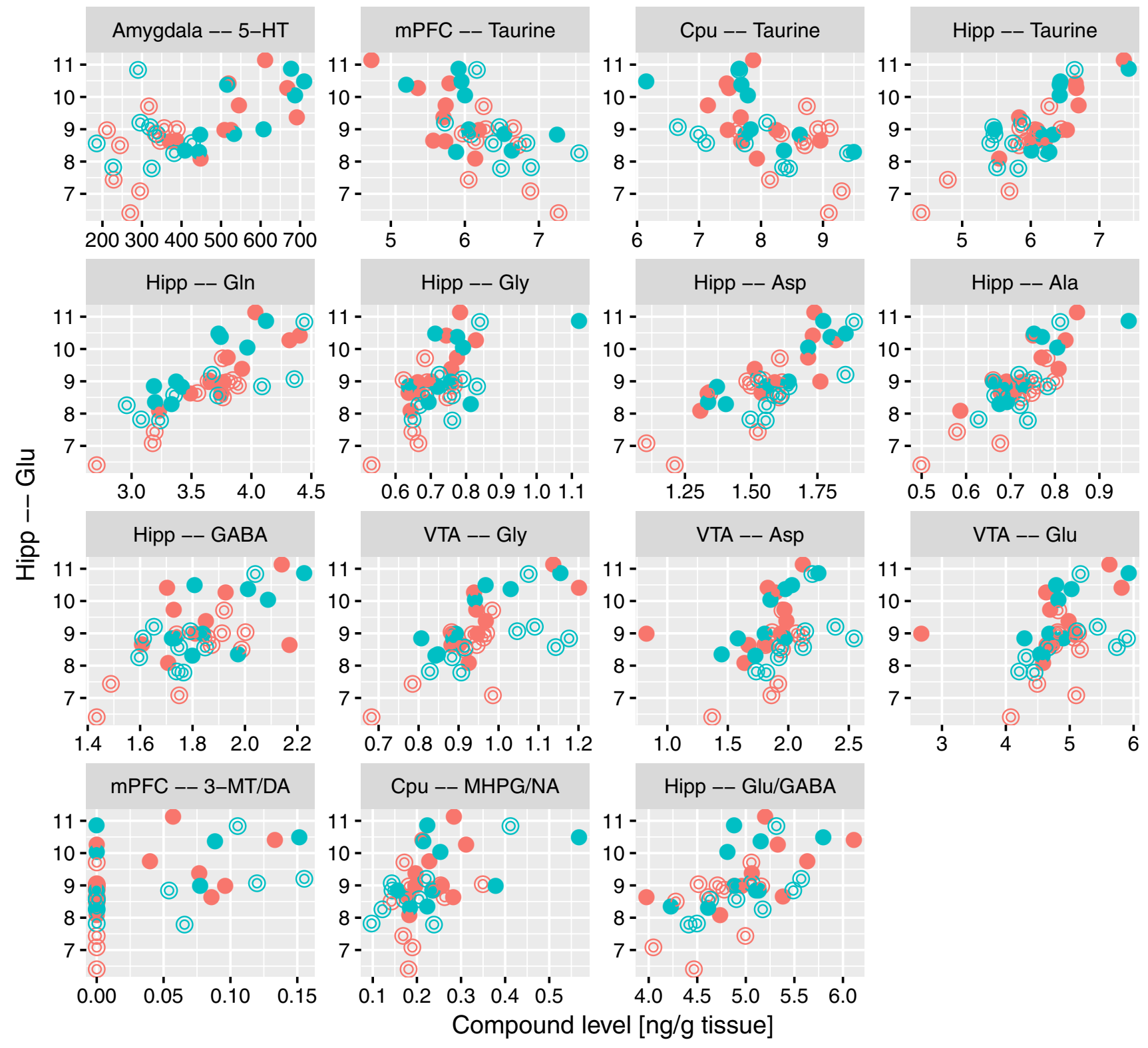

Day $\bigcirc$ d14 $\bullet$ d28 Injected $\bigcirc$ saline $\bigcirc$ morphine

Fig. 8 Relation between the level of glutamate in hippocampus and levels of compounds which were significantly correlated with it, shown as scatterplots

2001; Drummond 2000; Li et al. 2012). In rodents, incubation of craving has been demonstrated both in drug-treated animals (Grimm et al. 2001; Shalev et al. 2001; Shepard et al. 2004; Abdolahi et al. 2010) as well as in non-drug reward experiments (Grimm et al. 2002). Incubation of craving involves neuroadaptations in reward and motivationrelated structures (Conrad et al. 2008; Sesack and Grace 2010; Wolf and Tseng 2012; Lee et al. 2013; Purgianto et al. 2013; Ma et al. 2014; Pascoli et al. 2014; Li et al.
2015; Wolf 2016). It is well known that nucleus accumbens is key structure of the limbic system that is highly related to reward processing (Berridge 2007; Ikemoto 2007) and 50-kHz USVs emission (Thompson et al. 2006; Brudzynski 2013a, b; Hamed et al. 2016).

The present study shows that $50-\mathrm{kHz}$ USVs emission is associated with increased serotonin concentrations in amygdala, hippocampus and mPFC and also with elevated Glu/ Gln ratio in nucleus accumbens (Fig. 4; Table 1). Moreover, 


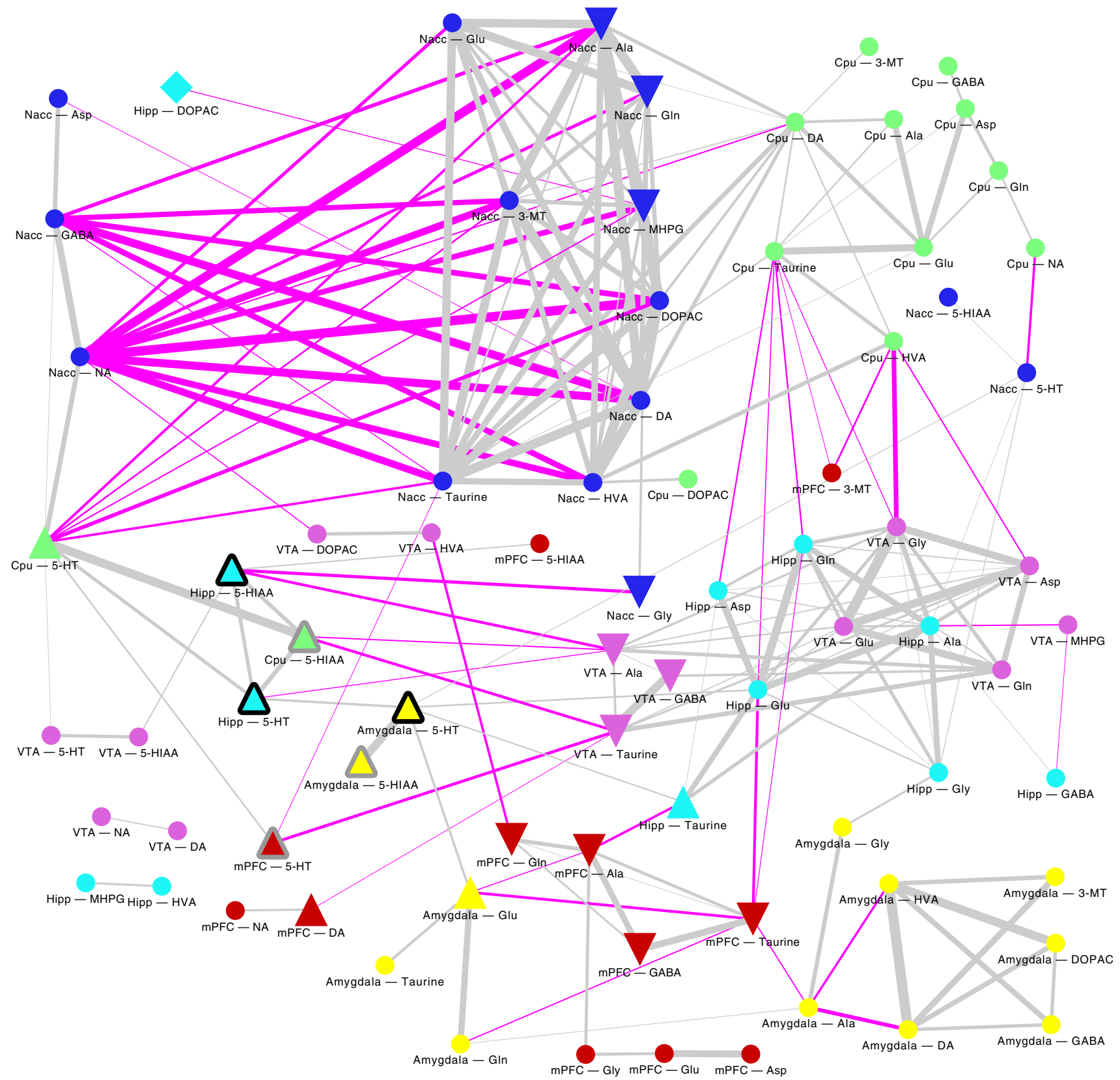

Fig. 9 Graph of significant correlations between compound levels. Node shape denotes significant relation with post-withdrawal conditioned response to the context, respectively: triangle up-level elevated in post-withdrawal conditioned response to the context, triangle down-lowered, square-interaction identified exclusively by machine learning. Node outline denotes significant relation with the
USV episode count, respectively: black outline-positive correlation, grey outline-interaction identified exclusively by machine learning. Edge with corresponds to the correlation strength, while its colour to the correlation sign: grey denotes positive, while fuchsia negative. Node colours denote brain structure

(Uejima et al. 2007; Li et al. 2008, 2015). Inhibition of CeA neuronal activity reduced incubation of nicotine, cocaine, methamphetamine and sucrose craving (Funk et al. 2016; Lu et al. 2005, 2007; Uejima et al. 2007; Li et al. 2015). Human fMRI studies report that amygdala is the key structure in the generation of cue-elicited opioid craving (Langleben et al. 
2008, 2014; Mei et al. 2010; Li et al. 2012; Murphy et al. 2017). It was found that GABA-ergic inhibition of neuronal activity leads to reduction of behavioral expression of craving ( $\mathrm{Li}$ et al. 2015). It was also demonstrated that ethanol withdrawal reduced GABA levels in medial prefrontal cortex and enhanced glutamate and glutamine levels in NAcc (Hinton et al. 2012). In our study, we found that GABA as well as alanine and taurine concentrations in $\mathrm{MPFC}$ are inversely proportional to the concentration of serotonin in the amygdala (Fig. 5) and the concentration of GABA in mPFC was decreased after withdrawal period. These data indicate that reduction of GABA-ergic inhibition in mPFC may be one of the initiating factors of drug-seeking behavior and expression of craving reflected by $50-\mathrm{kHz}$ USVs. We have also demonstrated for the first time that Glu/GABA ratio in VTA and amygdala was elevated after re-exposure to the drugpaired context on the day 28 compared to day 14 (Table 2).

It was demonstrated in optogenetic studies that silent synapse-based reorganization of the amygdala-to-accumbens projections plays key role in stability of cocaine craving and relapse after withdrawal period (Lee et al. 2013). Furthermore, it was found that mechanisms related to the action of MMP-9 (an important controller of the synaptic plasticity of excitatory synapses) in central amygdala are crucial in generating a motivation for reward seeking (Stefaniuk et al. 2017). An elevated glutamate concentration in amygdala which correlates with increased serotonin in this structure (Fig. 6), parallels an experiment in which the reduction of serotonergic neurotransmission in amygdala promoted hyperexcitability of this structure by enhancing glutamatergic neurotransmission, in consequence increasing fear related behaviors (Tran et al. 2013). It might further indicate that increased concentration of serotonin in this structure presented in our study, prevents or switches over the arousal from fear expression to appetitive arousal related to drug-seeking behavior expressed by $50-\mathrm{kHz}$ emission. Further investigations of mentioned neurochemicals co-existence in the amygdala have to be performed to address this hypothesis. Moreover, ex vivo electrophysiological recordings with optogenetic methods and pharmacological analysis revealed the existence of the 5-HT and glutamate co-transmission in basal amygdala neurons (Sengupta et al. 2017).

The very nature of the conditioned place preference is attributed to activation of the reward system and its association with information on the surrounding space during training sessions. This information in the hippocampus is represented by a subset of spatially tuned neurons called place cells (Hollup et al. 2001). The hippocampus and its inputs have been implicated in memory formation, including reward-related memory (Scoville and Milner 1957; Lisman and Grace 2005; Hernández-Rabaza et al. 2008; Bunzeck et al. 2011). Furthermore, it was demonstrated that a projection from area $\mathrm{CA} 3$ of dorsal hippocampus to ventral tegmental area (VTA) mediated relations between context and reward (Luo et al. 2011). Ntamati and Luscher identified and characterized a projection from VTA that releases both glutamate and GABA near the granule cells of hippocampal DG (Ntamati and Lüscher 2016).

We found that the level of serotonin in amygdala is directly proportional to the concentration of glutamate in amygdala and hippocampus as well as to the level of serotonin in nucleus accumbens and in the hippocampus (Fig. 5). Additionally, all-to-all analysis indicate that concentration of glutamate in hippocampus is directly proportional to glutamate level in VTA and GABA concentration in the hippocampus (Figs. 8,9 ).

There are potent structural interconnectivities and functional relationships between nucleus accumbens (Nacc), amygdala and hippocampus. Nucleus accumbens integrates cortical and limbic glutamatergic inputs arising from basolateral amygdala (BLA), hippocampal ventral subiculum (vSub) and prefrontal cortex (PFC) (Phillipson and Griffiths 1985; Groenewegen et al. 1987; McDonald 1991; Shinonaga et al. 1994; Johnson et al. 1994; O’Donnell and Grace 1995; Petrovich et al. 1996; Friedman et al. 2002; French and Totterdell 2003; Sesack and Grace 2010; Gill and Grace 2011; Britt et al. 2012).

It is well known that the amygdala is a structure involved in expression of the emotion and in learned emotional behaviors (LeDoux 2000). Previous studies have established that the BLA is involved in affective response and the vSub in context dependency (Gill and Grace 2011). Optogenetic studies revealed that selective activation of BLA, but not mPFC, glutamatergic inputs to the NAcc promotes motivated behavioral responding (Stuber et al. 2011). On the other hand, photostimulation of each of the different afferent pathways (vHipp, mPFC, BLA axons) to the NAcc reinforced instrumental behavior (Britt et al. 2012). Britt and colleagues suggested that the specific pathway releasing glutamate is not as important as the amount of glutamate that is released (Britt et al. 2012). Anatomical and functional interconnectivity of the amygdala and hippocampus has been demonstrated in a number of studies (Mello et al. 1992a, b; Maren and Fanselow 1995; Ikegaya et al. 1994, 1996a, b; Akirav and Richter-Levin 1999; Nakao et al. 2004).

We did not detect correlative association of glutamate level between hippocampus and amygdala, but we found strong relation between glutamate concentration in hippocampus and the serotonin level in amygdala (Figs. 8, 9). Considering the fact that the hippocampus is strictly involved in spatial memory formation, we can suppose that, after or during activation of hippocampus-VTA loop the hippocampus sends glutamatergic signal to the amygdala to amplify the serotonergic signaling. Then, 5-HT augmentation may initiate or support the glutamatergic signaling 
in amygdala. These processes might have a strong impact on the $50-\mathrm{kHz}$ USV s expression of emotions reflected in neurochemical changes in Glu/Gln ratio in Nacc. Understanding the sequence of activation of the neurochemical signaling between interacting structures requires further research using electrophysiological, optogenetic or voltammetric methodology.

Obtained neurochemical data confirms the contribution of amygdala, nucleus accumbens and hippocampus to spatial memory formation and memory processing bound up with enhanced emotional states (arousal) triggered by an appetitive conditioned context (Hall et al. 2001; Ito et al. 2006, 2008). Taking into account the strong serotoninergic response simultaneously in amygdala, nucleus accumbens, $\mathrm{mPFC}$ and hippocampus in processing context conditioned response, based on literature reports, it is reasonable to assume that the structure responsible for this increased levels of 5-HT was dorsal raphe. This structure represents one of the most sensitive reward sites in the brain (Yi Li et al. 2016; Luo et al. 2015, 2016; Matthews et al. 2016; Qi et al. 2014). It has been shown that the nucleus accumbens receives serotonin and non-serotonin inputs from dorsal raphe nucleus (Van Bockstaele and Pickel 1993; Brown and Molliver 2000). Unfortunately, because we did not expect such strong serotonin response in case of 50-kHz USVs emission, we did not analyze concentrations of the neurochemical compounds in dorsal raphe.

Rewards such as food, sucrose, social interaction or sex rapidly activate serotonin neurons in dorsal raphe (Yi Li et al. 2016). It was also demonstrated that dorsal raphe neurons encode reward via serotonin and glutamate (Liu et al. 2014). It is well known that SSRIs affecting the serotonergic system have been used extensively in the treatment of psychiatric disorders over past 20 years. In the studies using microdialysis methods, acute treatment with citalopram increased extracellular serotonin concentration in the central amygdala to 175\% (Bosker et al. 2001) of basal level and in the ventral hippocampus citalopram increased serotonin to $325 \%$ of the basal level (Cremers et al. 2000). It is also interesting that studies on dopamine-deficient mice have demonstrated that dopamine is not required for morphineinduced reward as measured by conditioned place preference (Hnasko et al. 2005), which indicates that dopaminergic mesolimbic system is not crucial for reward processing and acquisition. Hnasko et al. (2007) demonstrated that in mice with dopamine deficiency the fluoxetine at dose of $5.0 \mathrm{mg} / \mathrm{kg}$ produced robust conditioned place preference. This indicate that serotonin may mediate reward in the absence of dopamine (Hnasko et al. 2007).

It is well known that glutamate is the primary excitatory neurotransmitter in the nervous system (Sladeczek et al. 1985). Biochemical studies demonstrate that astrocytic glutamine plays a crucial role in sustaining excitatory neurotransmission (Hertz 1979; Tani et al. 2014). Given the presence of the physiological glutamate-glutamine cycle (Hertz 1979; Scofield and Kalivas 2014; Tani et al. 2014) we have analyzed the correlation of behavioral and biochemical data with Glu/Gln ratio in all examined structures. Analysis of another neurotransmitter/metabolite ratios were also done (see "Statistics").

We have shown for the first time that the number of USVs episodes strongly correlates with Glu/Gln ratio in nucleus accumbens (Fig. 4) and the increased Glu/Gln ratio in nucleus accumbens has strong associations with Glu/Gln ratio simultaneously in VTA, amygdala, $\mathrm{CPu}$ and hippocampus (Fig. 7). This parameter also positively correlates with concentrations of serotonin and its metabolite 5-HIAA in amygdala as well as with MHPG/NA ratio in CPu (Fig. 7). Increased levels of Glu/Gln ratio in amygdala presented in our study is interesting in light of data from electrochemical studies, which indicate that glutamate concentration in basolateral amygdala is transiently elevated by reward-predictive stimuli (Malvaez et al. 2015). Moreover, previous studies showed that blockade of the glia selective glutamate reuptake in the amygdala and in VTA induced depressivelike effects, including anhedonic symptoms manifested in reduced social interactions and reduced sensitivity to reward (Herberg and Rose 1990; Lee et al. 2007; Bechtholt-Gompf et al. 2010; John et al. 2012). It was also demonstrated that dentate gyrus of the hippocampus was the main structure responsible for this effect and impaired spatial memory was related to observed anhedonic symptoms (Bechtholt-Gompf et al. 2010). Furthermore, it was reported that decreased levels of astrocytic glutamate transporter occurred in animal models of depression (Zink et al. 2010). It is worth mentioning that the most commonly used anti-depressive drug fluoxetine (selective inhibitor of the serotoninergic transporter) induced astrocytic glutamate transporter expression in hippocampus, amygdala and retrosplenial granular cortex (Zink et al. 2011).

Thus, the relationship between the emission of $50-\mathrm{kHz}$ USVs and the neurochemical changes that occur after reexposure to morphine-paired context, indicates strong serotoninergic response in amygdala, hippocampus and mPFC enhanced with increased glutamatergic activity in nucleus accumbens. Most of the studies considering 'incubation craving' were carried out with more than 2 weeks of withdrawal period. Nevertheless, the time-dependent differentiation of behavioral response presented in our study indicate that context-induced $50-\mathrm{kHz}$ USV s emission might be a new tool for reflecting individual differences in incubation of craving. Presented analysis indicates a strong correlation between serotonergic and glutamatergic systems in contextinduced conditioned response. The strength of this co-transmission correlates with the number of $50-\mathrm{kHz}$ USVs emitted in response to the reward context. 


\section{Limitation of the study}

The limitation of the procedure is the lack of control in another environment that was not paired with morphine conditioning. This kind of neutral environment control would exclude chance that $50-\mathrm{kHz}$ USV s might be reflection of incubation of craving triggered without drug-associated spatial cues and the $50-\mathrm{kHz}$ USV s emission might be permanent after 14 days of withdrawal period. Nevertheless, contextinduced conditioning USV s was not observed in the first seconds of testing session and these sounds were intensifying with the time spent in the testing cage, probably after acquisition spatial cues.

Another limitation of our study is that the analysis of neurotransmitters concentration was performed post mortem, so there was a time lag between measurement of USV and measurement of neurochemical changes in the brain. However, animals were decapitated immediately after testing session and brain tissue of each animal was isolated strictly after that. It is well known that the advantage of the in vivo technique (voltammetry or microdialysis) is that it enables tracking of changes in the extracellular concentrations of neurotransmitters over time; however, monitoring is generally limited to changes in a single structure. The ex vivo method enables the analysis of not only the extracellular concentration but also the total concentration of neurotransmitters and their metabolites in several brain structures. According to our knowledge, there is no technological possibility to analyze concentration of many neurotransmitters and their metabolites in several structures in vivo in freely moving rats.

Acknowledgements This research was supported by Grant DEC2011/03/B/NZ7/04155 from the National Science Centre, Poland. The study was supported by the Institute of Psychiatry and Neurology statutory found no. 501-003-13-043. We would like to thank Danuta Turzyńska and Alicja Sobolewska from Institute of Psychiatry and Neurology (Department of Neurochemistry) for HPLC analysis. Many thanks to Tomasz Jaroszewski for co-creation of RatRec software, who provided us with recording and detailed analysis of the USVs FFT spectrograms.

\section{Compliance with ethical standards}

Conflict of interest There are no conflicts of interest related to this work.

Ethical statement The experiments were performed in accordance with the European Communities Council Directive of 24 November 1986 (86/609 EEC).

Study involving human and/or animal participants All applicable international, national, and/or institutional guidelines for the care and use of animals were followed. All experimental procedures using animal subjects were approved by the Local Committee for Animal Care and Use at Warsaw University of Medicine as compliant with Polish Law (21 of January 2005) (permission number: 20/2010). All proce- dures performed in studies involving animals were in accordance with the ethical standards of the institution or practice at which the studies were conducted. This article does not contain any studies with human participants performed by any of the authors.

Open Access This article is distributed under the terms of the Creative Commons Attribution 4.0 International License (http://creativeco mmons.org/licenses/by/4.0/), which permits unrestricted use, distribution, and reproduction in any medium, provided you give appropriate credit to the original author(s) and the source, provide a link to the Creative Commons license, and indicate if changes were made.

\section{References}

Abdolahi A, Acosta G, Breslin FJ, Hemby SE, Lynch WJ (2010) Incubation of nicotine seeking is associated with enhanced protein kinase A-regulated signaling of dopamine- and cAMP-regulated phosphoprotein of $32 \mathrm{kDa}$ in the insular cortex. Eur J Neurosci 31:733-741

Abrams DB, Monti PM, Carey KB, Pinto RP, Jacobus SI (1988) Reactivity to smoking cues and relapse: two studies of discriminant validity. Behav Res Ther 26:225-233

Ahrens AM, Ma ST, Maier EY, Duvauchelle CL, Schallert T (2009) Repeated intravenous amphetamine exposure: rapid and persistent sensitization of $50-\mathrm{kHz}$ ultrasonic trill calls in rats. Behav Brain Res 197(1):205-209

Akirav I, Richter-Levin G (1999) Priming stimulation in the basolateral amygdala modulates synaptic plasticity in the rat dentate gyrus. Neurosci Lett 270:83-86

Bechtholt-Gompf AJ, Walther HV, Adams MA, Carlezon WA Jr, Ongür D, Cohen BM (2010) Blockade of astrocytic glutamate uptake in rats induces signs of anhedonia and impaired spatial memory. Neuropsychopharmacology 35(10):2049-2059

Benjamini Y, Hochberg Y (1995) Controlling the false discovery rate: a practical and powerful approach to multiple testing. J R Stat Soc Ser B 57(1):289-300

Berridge KC (2007) The debate over dopamine's role in reward: the case for incentive salience. Psychopharmacology 191:391-431

Bosker FJ, Cremers TI, Jongsma ME, Westerink BH, Wikström HV, den Boer JA (2001) Acute and chronic effects of citalopram on postsynaptic 5-hydroxytryptamine( $1 \mathrm{~A})$ receptor-mediated feedback: a microdialysis study in the amygdala. J Neurochem 76(6):1645-1653

Breiman L (2001) Random forests. Mach Learn 45:5-32

Britt JP, Benaliouad F, McDevitt RA, Stuber GD, Wise RA, Bonci A (2012) Synaptic and behavioral profile of multiple glutamatergic inputs to the nucleus accumbens. Neuron 76:790-803

Bromberg-Martin ES, Matsumoto M, Hikosaka O (2010) Dopamine in motivational control: rewarding, aversive, and alerting. Neuron $68(5): 815-834$

Brown P, Molliver ME (2000) Dual serotonin (5-HT) projections to the nucleus accumbens core and shell: relation of the 5-HT transporter to amphetamine-induced neurotoxicity. J Neurosci 20(5):1952-1963

Brudzynski SM (2013a) Ethotransmission: communication of emotional states through ultrasonic vocalization in rats. Curr Opin Neurobiol 23:310-317

Brudzynski SM (2013b) Ethotransmission: communication of emotional states through ultrasonic vocalization in rats. Curr Opin Neurobiol 23(3):310-317

Brudzynski SM, Pniak A (2002) Social contacts and production of $50-\mathrm{kHz}$ short ultrasonic calls in adult rats. J Comp Psychol 116(1):73-82 
Brudzynski SM, Silkstone M, Komadoski M, Scullion K, Duffus S, Burgdorf J, Kroes RA, Moskal JR, Panksepp J (2011) Effects of intraaccumbens amphetamine on production of $50 \mathrm{kHz}$ vocalizations in three lines of selectively bred Long-Evans rats. Behav Brain Res 217(1):32-40

Buck CL, Vendruscolo LF, Koob GF, George O (2014) Dopamine D1 and mu-opioid receptor antagonism blocks anticipatory $50 \mathrm{kHz}$ ultrasonic vocalizations induced by palatable food cues in Wistar rats. Psychopharmacology 231:929-937

Bunzeck N, Guitart-Masip M, Dolan RJ, Düzel E (2011) Contextual novelty modulates the neural dynamics of reward anticipation. J Neurosci 31(36): 12816-12822

Burgdorf J, Knutson B, Panksepp J (2000) Anticipation of rewarding electrical brain stimulation evokes ultrasonic vocalization in rats. Behav Neurosci 114(2):320-327

Burgdorf J, Knutson B, Panksepp J, Ikemoto S (2001) Nucleus accumbens amphetamine microinjections unconditionally elicit $50-\mathrm{kHz}$ ultrasonic vocalization in rats. Behav Neurosci 115:940-944

Burgdorf J, Wood P, Kroes R, Moskal J, Panksepp J (2007) Neurobiology of $50 \mathrm{kHz}$ ultrasonic vocalization in rats: electrode mapping, lesion, and pharmacology studies. Behav Brain Res 182:274-283

Burgdorf J, Colechio EM, Stanton P, Panksepp J (2017) Positive emotional learning induces resilience to depression: a role for NMDA receptor-mediated synaptic plasticity. Curr Neuropharmacol 15(1):3-10

Cohen JY, Haesler S, Vong L, Lowell BB, Uchida N (2012) Neurontype-specific signals for reward and punishment in the ventral tegmental area. Nature 482:85-88

Conrad KL, Tseng KY, Uejima JL, Reimers JM, Heng LJ, Shaham Y, Marinelli M, Wolf ME (2008) Formation of accumbens GluR2lacking AMPA receptors mediates incubation of cocaine craving. Nature 454:118-121

Costa G, Morelli M, Simola N (2015) Involvement of glutamate NMDA receptors in the acute, long-term, and conditioned effects of amphetamine on rat $50 \mathrm{kHz}$ ultrasonic vocalizations. Int $\mathbf{J}$ Neuropsychopharmacol 18(11):pyv057

Cremers TI, de Boer P, Liao Y, Bosker FJ, den Boer JA, Westerink BH, Wikström HV (2000) Augmentation with a 5-HT(1A), but not a 5-HT(1B) receptor antagonist critically depends on the dose of citalopram. Eur J Pharmacol 397(1):63-74

Dayan P, Balleine BW (2002) Reward, motivation, and reinforcement learning. Neuron 36:285-298

Drummond DC (2000) What does cue-reactivity have to offer clinical research? Addiction 95:129-144

Drummond DC, Cooper T, Glautier SP (1990) Conditioned learning in alcohol dependence: implications for cue exposure treatment. Br J Addict 85:725-743

French SJ, Totterdell S (2003) Individual nucleus accumbens-projection neurons receive both basolateral amygdala and ventral subicular afferents in rats. Neuroscience 119(1):19-31

Friedman DP, Aggleton JP, Saunders RC (2002) Comparison of hippocampal, amygdala, and perirhinal projections to the nucleus accumbens: combined anterograde and retrograde tracing study in the macaque brain. J Comp Neurol 450:345-365

Fu XW, Brudzynski SM (1994) High-frequency ultrasonic vocalization induced by intracerebral glutamate in rats. Pharmacol Biochem Behav 49(4):835-841

Funk D, Coen K, Tamadon S, Hope BT, Shaham Y, Lê AD (2016) Role of central amygdala neuronal ensembles in incubation of nicotine. Craving J Neurosci 36(33):8612-8623

Gawin FH, Kleber HD (1986) Abstinence symptomatology and psychiatric diagnosis in cocaine abusers. Clinical observations. Arch Gen Psychiatry 43:107-113

George MS, Anton RF, Bloomer C, Teneback Ch, Drobes DJ, Lorberbaum JP, Nahas Z, Vincent DJ (2001) Activation of prefrontal cortex and anterior thalamus in alcoholic subjects on exposure to alcohol-specific cues. Arch Gen Psychiatry 58:345-352

Gill KM, Grace AA (2011) Heterogeneous processing of amygdala and hippocampal inputs in the rostral and caudal subregions of the nucleus accumbens. Int J Neuropsychopharmacol 14(10):1301-1314

Grimm JW, Hope BT, Wise RA, Shaham Y (2001) Neuroadaptation. Incubation of cocaine craving after withdrawal. Nature 412:141-142

Grimm JW, Shaham Y, Hope BT (2002) Effect of cocaine and sucrose withdrawal period on extinction behavior, cue-induced reinstatement, and protein levels of the dopamine transporter and tyrosine hydroxylase in limbic and cortical areas in rats. Behav Pharmacol 13:379-388

Groenewegen HJ, Vermeulen-Van der Zee E, te Kortschot A, Witter MP (1987) Organization of the projections from the subiculum to the ventral striatum in the rat. A study using anterograde transport of Phaseolus vulgaris leucoagglutinin. Neuroscience 23(1):103-120

Hall J, Thomas KL, Everitt BJ (2001) Cellular imaging of zif268 expression in the hippocampus and amygdala during contextual and cued fear memory retrieval: selective activation of hippocampal CA1 neurons during the recall of contextual memories. J Neurosci 21:2186-2193

Hamed A, Jaroszewski T, Maciejak P, Szyndler J, Lehner M, Kamecka I, Plaznik A (2009) The effects of buspirone and diazepam on aversive context- and social isolation-induced ultrasonic vocalization. Physiol Behav 98:474-480

Hamed A, Taracha E, Szyndler J, Krząścik P, Lehner M, Maciejak P, Skórzewska A, Płaźnik A (2012) The effects of morphine and morphine conditioned context on $50 \mathrm{kHz}$ ultrasonic vocalisation in rats. Behav Brain Res 229(2):447-450

Hamed A, Szyndler J, Taracha E, Turzyńska D, Sobolewska A, Lehner M, Krzaścik P, Daszczuk P (2015) א-opioid receptor as a key mediator in the regulation of appetitive $50-\mathrm{kHz}$ ultrasonic vocalizations. Psychopharmacology 232(11):1941-1955

Hamed A, Daszczuk P, Kursa MB, Turzyńska D, Sobolewska A, Lehner M, Boguszewski PM, Szyndler J (2016) Non-parametric analysis of neurochemical effects and Arc expression in amphetamine-induced 50-kHz ultrasonic vocalization. Behav Brain Res 312:174-185

Herberg LJ, Rose IC (1990) Excitatory amino acid pathways in brainstimulation reward. Behav Brain Res 20(3):230-239

Hernández-Rabaza V, Hontecillas-Prieto L, Velázquez-Sánchez C, Ferragud A, Pérez-Villaba A, Arcusa A, Barcia JA, Trejo JL, Canales JJ (2008) The hippocampal dentate gyrus is essential for generating contextual memories of fear and drug-induced reward. Neurobiol Learn Mem 90:553-559

Hertz L (1979) Functional interactions between neurons and astrocytes I. Turnover and metabolism of putative amino acid transmitters. Prog Neurobiol 13(3):277-323

Hinton DJ, Lee MR, Jacobson TL, Mishra PK, Frye MA, Mrazek DA, Macura SI, Doo-Sup C (2012) Ethanol withdrawal-induced brain metabolites and the pharmacological effects of acamprosate in mice lacking ENT1. Neuropharmacology 62(8):2480-2488

Hnasko TS, Sotak BN, Palmiter RD (2005) Morphine reward in dopamine-deficient mice. Nature 438(7069):854-857

Hnasko TS, Sotak BN, Palmiter RD (2007) Cocaine-conditioned place preference by dopamine-deficient mice is mediated by serotonin. J Neurosci 27(46):12484-12488

Hollup SA, Molden S, Donnett JG, Moser MB, Moser EI (2001) Place fields of rat hippocampal pyramidal cells and spatial learning in the watermaze. Eur J Neurosci 13(6): 1197-1208

Holm S (1979) A simple sequentially rejective multiple test procedure. Scand J Stat 6:65-70 
Ikegaya Y, Saito H, Abe K (1994) Attenuated hippocampal longterm potentiation in basolateral amygdala-lesioned rats. Brain Res 656:157-164

Ikegaya Y, Saito H, Abe K (1996a) Dentate gyrus field potentials evoked by stimulation of the basolateral amygdaloid nucleus in anesthetized rats. Brain Res 718:53-60

Ikegaya Y, Saito H, Abe K (1996b) The basomedial and basolateral amygdaloid nuclei contribute to the induction of longterm potentiation in the dentate gyrus in vivo. Eur J Neurosci 8:1833-1839

Ikemoto S (2007) Dopamine reward circuitry: two projection systems from the ventral midbrain to the nucleus accumbens-olfactory tubercle complex. Brain Res Rev 56:27-78

Ito R, Robbins TW, McNaughton BL, Everitt BJ (2006) Selective excitotoxic lesions of the hippocampus and basolateral amygdala have dissociable effects on appetitive cue and place conditioning based on path integration in a novel Y-maze procedure. Eur J Neurosci 23(11):3071-3080

Ito R, Robbins TW, Pennartz CM, Everitt BJ (2008) Functional interaction between the hippocampus and nucleus accumbens shell is necessary for the acquisition of appetitive spatial context conditioning. J Neurosci 28(27):6950-6959

John CS, Smith KL, Van't Veer A, Gompf HS, Carlezon WA Jr, Cohen BM, Öngür D, Bechtholt-Gompf AJ (2012) Blockade of astrocytic glutamate uptake in the prefrontal cortex induces anhedonia. Neuropsychopharmacology 37(11):2467-2475

Johnson SW, North RA (1992) Opioids excite dopamine neurons by hyperpolarization of local interneurons. J Neurosci 12(2):483-488

Johnson LR, Aylward RL, Hussain Z, Totterdell S (1994) Input from the amygdala to the rat nucleus accumbens: its relationship with tyrosine hydroxylase immunoreactivity and identified neurons. Neuroscience 61(4):851-865

Kaneda N, Asano M, Nagatsu T (1986) Simple method for simultaneous determination of acetylcholine, choline, noradrenaline, dopamine and serotonin in brain tissue by high-performance liquid chromatography with electrochemical detection. J Chromatogr 36:211-218

Knutson B, Burgdorf J, Panksepp J (1998) Anticipation of play elicits high-frequency ultrasonic vocalizations in young rats. J Comp Psychol 112:65-73

Knutson B, Burgdorf J, Panksepp J (1999) High-frequency ultrasonic vocalizations index conditioned pharmacological reward in rats. Physiol Behav 66(4):639-643

Koob GF (1992) Drug of abuse: anatomy, pharmacology and function of reward pathways. Trands Pharmacol Sci 13:177-184

Kursa MB, Rudnicki WR (2010) Feature selection with the Boruta Package. J Stat Softw 36(11):1-13. http://www.jstatsoft.org/v36/ i11/

Lammel S, Ion DI, Roeper J, Malenka RC (2011a) Projection-specific modulation of dopamine neuron synapses by aversive and rewarding stimuli. Neuron 70:855-862

Lammel S, Ion DI, Roeper J, Malenka RC (2011b) Projection-specific modulation of dopamine neuron synapses by aversive and rewarding stimuli. Neuron 70(5):855-862

Lammel S, Lim BK, Ran C, Huang KW, Betley MJ, Tye KM, Deisseroth K, Malenka RC (2012) Input-specific control of reward and aversion in the ventral tegmental area. Nature 491:212-217

Langleben DD, Ruparel K, Elman I, Busch-Winokur S, Pratiwadi R, Loughead J, O'Brien CP, Childress AR (2008) Acute effect of methadone maintenance dose on brain FMRI response to heroinrelated cues. Am J Psychiatry 165:390-394

Langleben DD, Ruparel K, Elman I, Loughead JW, Busch EL, Cornish J, Lynch KG, Nuwayser ES, Childress AR, O'Brien CP (2014) Extended-release naltrexone modulates brain response to drug cues in abstinent heroin-dependent patients. Addict Biol 19:262-271

LeDoux JE (2000) Emotion circuits in the brain. Annu Rev Neurosci 23:155-184

Lee Y, Gaskins D, Anand A, Shekhar A (2007) Glia mechanisms in mood regulation: a novel model of mood disorders. Psychopharmacology 191(1):55-65

Lee BR, Ma YY, Huang YH, Wang X, Otaka M, Ishikawa M, Neumann PA, Graziane NM, Brown TE, Suska A, Guo C, Lobo MK, Sesack SR, Wolf ME, Nestler EJ, Shaham Y, Schluter OM, Dong Y (2013) Maturation of silent synapses in amygdala-accumbens projection contributes to incubation of cocaine craving. Nat Neurosci 16:1644-1651

Li YQ, Li FQ, Wang XY, Wu P, Zhao M, Xu CM, Shaham Y, Lu L (2008) Central amygdala extracellular signal-regulated kinase signaling pathway is critical to incubation of opiate craving. $\mathrm{J}$ Neurosci 28:13248-13257

Li Q, Wang Y, Zhang Y, Li W, Yang W, Zhu J, Wu N, Chang H, Zheng Y, Qin W, Zhao L, Yuan K, Liu J, Wang W, Tian J (2012) Craving correlates with mesolimbic responses to heroin-related cues in short-term abstinence from heroin: an event-related fMRI study. Brain Res 1469:63-72

Li X, Zeric T, Kambhampati S, Bossert JM, Shaham Y (2015) The central amygdala nucleus is critical for incubation of methamphetamine craving. Neuropsychopharmacology 40(5):1297-1306

Li Y, Zhong W, Wang D, Feng Q, Liu Z, Zhou J, Jia C, Hu F, Zeng J, Guo Q, Fu L, Luo M (2016) Serotonin neurons in the dorsal raphe nucleus encode reward signals. Nat Commun 7:10503

Li Y, Zhong W, Wang D, Feng Q, Liu Z, Zhou J, Jia C, Hu F, Zeng J, Guo Q, Fu L, Luo M (2016) Serotonin neurons in the dorsal raphe nucleus encode reward signals. Nat Commun 7:10503

Lisman JE, Grace AA (2005) The hippocampal-VTA loop: controlling the entry of information into long-term memory. Neuron 46(5):703-713

Liu Z, Zhou J, Li Y, Hu F, Lu Y, Ma M, Feng Q, Zhang JE, Wang D, Zeng J, Bao J, Kim JY, Chen ZF, El Mestikawy S, Luo M (2014) Dorsal raphe neurons signal reward through 5-HT and glutamate. Neuron 81(6):1360-1374

Lu L, Hope BT, Dempsey J, Liu SY, Bossert JM, Shaham Y (2005) Central amygdala ERK signaling pathway is critical to incubation of cocaine craving. Nat Neurosci 8(2):212-219

Lu L, Uejima JL, Gray SM, Bossert JM, Shaham Y (2007) Systemic and central amygdala injections of the mGluR(2/3) agonist LY379268 attenuate the expression of incubation of cocaine craving. Biol Psychiatry 61(5):591-598

Luo AH, Tahsili-Fahadan P, Wise RA, Lupica CR, Aston-Jones G (2011) Linking context with reward: a functional circuit from hippocampal CA3 to ventral tegmental area. Science 15(6040):353-357

Luo M, Zhou J, Liu Z (2015) Reward processing by the dorsal raphe nucleus: 5-HT and beyond. Learn Mem 22(9):452-460

Luo M, Li Y, Zhong W (2016) Do dorsal raphe 5-HT neurons encode "beneficialness"? Neurobiol Learn Mem 135:40-49

Ma YY, Lee BR, Wang X, Guo C, Liu L, Cui R, Lan Y, Balcita-Pedicino JJ, Wolf ME, Sesack SR, Shaham Y, Schlüter OM, Huang YH, Dong Y (2014) Bidirectional modulation of incubation of cocaine craving by silent synapse-based remodeling of prefrontal cortex to accumbens projections. Neuron 83:1453-1467

Malvaez M, Greenfield VY, Wang AS, Yorita AM, Feng L, Linker KE, Monbouquette HG, Wassum KM (2015) Basolateral amygdala rapid glutamate release encodes an outcome-specific representation vital for reward-predictive cues to selectively invigorate reward-seeking actions. Sci Rep 5:12511

Maren S, Fanselow MS (1995) Synaptic plasticity in the basolateral amygdala induced by hippocampal formation stimulation in vivo. J Neurosci 15(11):7548-7564 
Matthews GA, Nieh EH, Vander Weele CM, Halbert SA, Pradhan RV, Yosafat AS, Glober GF, Izadmehr EM, Thomas RE, Lacy GD, Wildes CP, Ungless MA, Tye KM (2016) Dorsal raphe dopamine neurons represent the experience of social isolation. Cell 164(4):617-631

McDonald AJ (1991) Topographical organization of amygdaloid projections to the caudatoputamen, nucleus accumbens, and related striatal-like areas of the rat brain. Neuroscience 44(1):15-33

Mei W, Zhang JX, Xiao Z (2010) Acute effects of sublingual buprenorphine on brain responses to heroin-related cues in early-abstinent heroin addicts: an uncontrolled trial. Neuroscience 170:808-815

Mello LE, Tan AM, Finch DM (1992a) GABAergic synaptic transmission in projections from the basal forebrain and hippocampal formation to the amygdala: an in vivo iontophoretic study. Brain Res 31:41-48. 88

Mello LE, Tan AM, Finch DM (1992b) Convergence of projections from the rat hippocampal formation, medial geniculate and basal forebrain onto single amygdaloid neurons: an in vivo extra- and intracellular electrophysiological study. Brain Res 31:24-40

Murphy A, Lubman DI, McKie S, Bijral PS, Peters LA, Faiz Q, Holmes SE, Anderson IM, Deakin B, Elliott R (2017) Time-dependent neuronal changes associated with craving in opioid dependence: an fMRI study. Addict Biol. https://doi.org/10.1111/adb.12554

Nagai T, Yamada K, Yoshimura M, Ishikawa K, Miyamoto Y, Hashimoto K, Noda Y, Nitta A, Nabeshima T (2004) The tissue plasminogen activator-plasmin system participates in the rewarding effect of morphine by regulating dopamine release. Proc Natl Acad Sci USA 101(10):3650-3655

Nakao K, Matsuyama K, Matsuki N, Ikegaya Y (2004) Amygdala stimulation modulates hippocampal synaptic plasticity. Proc Natl Acad Sci USA 101(39):14270-14275

Ntamati NR, Lüscher C (2016) VTA projection neurons releasing GABA and glutamate in the dentate gyrus. eNeuro 3(4)

O'Donnell P, Grace AA (1995) Synaptic interactions among excitatory afferents to nucleus accumbens neurons: hippocampal gating of prefrontal cortical input. J Neurosci 15(5 Pt 1):3622-3639

Opiol H, Pavlovski I, Michalik M, Mistlberger RE (2015) Ultrasonic vocalizations in rats anticipating circadian feeding schedules. Behav Brain Res 284:42-50

Panksepp J, Burgdorf J (2003) "Laughing" rats and the evolutionary antecedents of human joy? Physiol Behav 79(3):533-547

Pascoli V, Terrier J, Espallergues J, Valjent E, O'Connor EC, Lüscher C (2014) Contrasting forms of cocaine-evoked plasticity control components of relapse. Nature 509(7501):459-464

Paxinos G, Watson C (1998) The rat brain in stereotaxic coordinates. Academic Press, San Diego

Petrovich GD, Risold PY, Swanson LW (1996) Organization of projections from the basomedial nucleus of the amygdala: a PHAL study in the rat. J Comp Neurol 374(3):387-420

Phillipson OT, Griffiths AC (1985) The topographic order of inputs to nucleus accumbens in the rat. Neuroscience 16(2):275-296

Purgianto A, Scheyer AF, Loweth JA, Ford KA, Tseng KY, Wolf ME (2013) Different adaptations in AMPA receptor transmission in the nucleus accumbens after short vs long access cocaine self-administration regimens. Neuropsychopharmacology 38(9):1789-1797

Qi J, Zhang S, Wang HL, Wang H, de Jesus Aceves Buendia J, Hoffman AF, Lupica CR, Seal RP, Morales M (2014) A glutamatergic reward input from the dorsal raphe to ventral tegmental area dopamine neurons. Nat Commun 5:5390

R Core Team (2017) R: a language and environment for statistical computing. R Foundation for Statistical Computing, Vienna. http:// www.R-project.org/

Rowley HL, Martin KF, Marsden CA (1995) Determination of in vivo amino acid neurotransmitters by high-performance liquid chromatography with $o$-phthalaldehyde-sulphite derivatisation. J Neurosci Methods 57:93-99

Sadananda M, Natusch C, Karrenbauer B, Schwarting RK (2012) $50-\mathrm{kHz}$ calls in rats: effects of MDMA and the 5-HT(1A) receptor agonist 8-OH-DPAT. Pharmacol Biochem Behav 10:258-264

Savicky P (2014) pspearman: Spearman's rank correlation test. R package version 0.3-0. https://CRAN.R-project.org/package=pspea rman

Schultz W, Dayan P, Montague PR (1997) A neural substrate of prediction and reward. Science 275:1593-1599

Scofield MD, Kalivas PW (2014) Astrocytic dysfunction and addiction: consequences of impaired glutamate homeostasis. Neuroscientist 20(6):610-622

Scoville WB, Milner B (1957) Loss of recent memory after bilateral hippocampal lesions. J Neurol Neurosurg Psychiatry 20:11-21

Sengupta A, Bocchio M, Bannerman DM, Sharp T, Capogna M (2017) Control of amygdala circuits by 5-HT neurons via 5-HT and glutamate cotransmission. J Neurosci 37(7):1785-1796

Sesack SR, Grace AA (2010) Cortico-basal ganglia reward network: microcircuitry. Neuropsychopharmacology 35(1):27-47

Shalev U, Morales M, Hope B, Yap J, Shaham Y (2001) Time-dependent changes in extinction behavior and stress-induced reinstatement of drug seeking following withdrawal from heroin in rats. Psychopharmacology 156:98-107

Shepard JD, Bossert JM, Liu SY, Shaham Y (2004) The anxiogenic drug yohimbine reinstates methamphetamine seeking in a rat model of drug relapse. Biol Psychiatry 55:1082-1089

Shinonaga Y, Takada M, Mizuno N (1994) Topographic organization of collateral projections from the basolateral amygdaloid nucleus to both the prefrontal cortex and nucleus accumbens in the rat. Neuroscience 58(2):389-397

Simola N, Fenu S, Costa G, Pinna A, Plumitallo A, Morelli M (2012) Pharmacological characterization of 50-kHz ultrasonic vocalizations in rats: comparison of the effects of different psychoactive drugs and relevance in drug-induced reward. Neuropharmacology 63:224-234

Sladeczek F, Pin JP, Recasens M, Bockaert J, Weiss S (1985) Glutamate stimulates inositol phosphate formation in striatal neurones. Nature 317:717-719

Stefaniuk M, Beroun A, Lebitko T, Markina O, Leski S, Meyza K, Grzywacz A, Samochowiec J, Samochowiec A, Radwanska K, Kaczmarek L (2017) Matrix metalloproteinase-9 and synaptic plasticity in the central amygdala in control of alcohol-seeking behavior. Biol Psychiatry 81(11):907-917

Stuber GD, Sparta DR, Stamatakis AM, van Leeuwen WA, Hardjoprajitno JE, Cho S, Tye KM, Kempadoo KA, Zhang F, Deisseroth K, Bonci A (2011) Excitatory transmission from the amygdala to nucleus accumbens facilitates reward seeking. Nature 475:377-380

Szyndler J, Maciejak P, Turzyńska D, Sobolewska A, Lehner M, Taracha E, Walkowiak J, Skórzewska A, Wisłowska-Stanek A, Hamed A, Bidziński A, Plaznik A (2008) Changes in the concentration of amino acids in the hippocampus of pentylenetetrazolekindled rats. Neurosci Lett 439:245-249

Szyndler J, Maciejak P, Turzyńska D, Sobolewska A, Bidziński A, Plaznik A (2010) Time course of changes in the concentrations of monoamines in the brain structures of pentylenetetrazole-kindled rats. J Neural Transm 117:707-718

Tani H, Dulla CG, Farzampour Z, Taylor-Weiner A, Huguenard JR, Reimer RJ (2014) A local glutamate-glutamine cycle sustains synaptic excitatory transmitter release. Neuron 19(4):888-900

Taracha E, Hamed A, Krzaścik P, Lehner M, Skórzewska A, Płaźnik A, Chrapusta SJ (2012) Inter-individual diversity and intraindividual stability of amphetamine-induced sensitization of 
frequency-modulated $50-\mathrm{kHz}$ vocalization in Sprague-Dawley rats. Psychopharmacology 222(4):619-632

Thompson B, Leonard KC, Brudzynski SM (2006) Amphetamineinduced $50 \mathrm{kHz}$ calls from rat nucleus accumbens: a quantitative mapping study and acoustic analysis. Behav Brain Res 168(1):64-73

Tran L, Lasher BK, Young KA, Keele NB (2013) Depletion of serotonin in the basolateral amygdala elevates glutamate receptors and facilitates fear-potentiated startle. Transl Psychiatry 3:e298

Uejima JL, Bossert JM, Poles GC, Lu L (2007) Systemic and central amygdala injections of the mGluR2/3 agonist LY379268 attenuate the expression of incubation of sucrose craving in rats. Behav Brain Res 181(2):292-296

Van Bockstaele EJ, Pickel VM (1993) Ultrastructure of serotoninimmunoreactive terminals in the core and shell of the rat nucleus accumbens: cellular substrates for interactions with catecholamine afferents. J Comp Neurol 334(4):603-617

Wang H, Liang S, Burgdorf J, Wess J, Yeomans J (2008) Ultrasonic vocalizations induced by sex and amphetamine in M2, M4, M5 muscarinic and D2 dopamine receptor knockout mice. PLoS One 3(4):e1893

Wintink AJ, Brudzynski SM (2001) The related roles of dopamine and glutamate in the initiation of $50-\mathrm{kHz}$ ultrasonic calls in adult rats. Pharmacol Biochem Behav 70(2-3):317-323

Wöhr M, Rippberger H, Schwarting RK, van Gaalen MM (2015) Critical involvement of 5-HT2C receptor function in amphetamineinduce $50-\mathrm{kHz}$ ultrasonic vocalizations in rats. Psychopharmacology 232(10):1817-1829

Wolf ME (2016) Synaptic mechanisms underlying persistent cocaine craving. Nat Rev Neurosci 17:351-365

Wolf ME, Tseng KY (2012) Calcium-permeable AMPA receptors in the VTA and nucleus accumbens after cocaine exposure: when, how, and why? Front Mol Neurosci 5:72
Wright MN, Ziegler A (2017) ranger: a fast implementation of random forests for high dimensional data in $\mathrm{C}++$ and R. J Stat Softw 77(1):1-17

Wright JM, Gourdon JC, Clarke PB (2010) Identification of multiple call categories within the rich repertoire of adult rat $50-\mathrm{kHz}$ ultrasonic vocalizations: effects of amphetamine and social context. Psychopharmacology 211(1):1-13

Wright JM, Dobosiewicz MR, Clarke PB (2012a) $\alpha$ - and $\beta$-adrenergic receptors differentially modulate the emission of spontaneous and amphetamine-induced $50-\mathrm{kHz}$ ultrasonic vocalizations in adult rats. Neuropsychopharmacology 37(3):808-821

Wright JM, Deng L, Clarke PB (2012b) Failure of rewarding and locomotor stimulant doses of morphine to promote adult rat $50-\mathrm{kHz}$ ultrasonic vocalizations. Psychopharmacology (Berl) 224(4):477-487

Wright JM, Dobosiewicz MR, Clarke PB (2013) The role of dopaminergic transmission through D1-like and D2-like receptors in amphetamine-induced rat ultrasonic vocalizations. Psychopharmacology 225(4):853-868

Zink M, Vollmayr B, Gebicke-Haerter PJ, Henn FA (2010) Reduced expression of glutamate transporters vGluT1, EAAT2 and EAAT4 in learned helpless rats, an animal model of depression. Neuropharmacology 58(2):465-473

Zink M, Rapp S, Donev R, Gebicke-Haerter PJ, Thome J (2011) Fluoxetine treatment induces EAAT2 expression in rat brain. J Neural Transm 118(6):849-855

Zweifel LS, Fadok JP, Argilli E, Garelick MG, Jones GL, Dickerson TM, Allen JM, Mizumori SJ, Bonci A, Palmiter RD (2011) Activation of dopamine neurons is critical for aversive conditioning and prevention of generalized anxiety. 14(5):620-626 